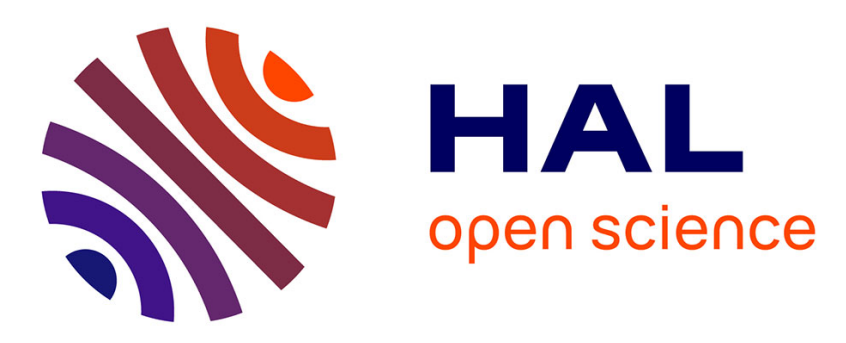

\title{
Smectite quantification in hydrothermally altered volcanic rocks
}

\author{
Léa Lévy, Thráinn Fridriksson, Nathaniel Findling, Bruno Lanson, Bernard \\ Fraisse, Nicolas Marino, Benoit Gibert
}

\section{- To cite this version:}

Léa Lévy, Thráinn Fridriksson, Nathaniel Findling, Bruno Lanson, Bernard Fraisse, et al.. Smectite quantification in hydrothermally altered volcanic rocks. Geothermics, 2020, 85, pp.101748. 10.1016/j.geothermics.2019.101748 . insu-03043134

\section{HAL Id: insu-03043134 https://hal-insu.archives-ouvertes.fr/insu-03043134}

Submitted on 7 Dec 2020

HAL is a multi-disciplinary open access archive for the deposit and dissemination of scientific research documents, whether they are published or not. The documents may come from teaching and research institutions in France or abroad, or from public or private research centers.
L'archive ouverte pluridisciplinaire $\mathbf{H A L}$, est destinée au dépôt et à la diffusion de documents scientifiques de niveau recherche, publiés ou non, émanant des établissements d'enseignement et de recherche français ou étrangers, des laboratoires publics ou privés. 


\title{
Smectite quantification in hydrothermally
}

\author{
altered volcanic rocks
}

\author{
Léa Lévy ${ }^{1,2}$, Thráinn Fridriksson ${ }^{3}$, Nathaniel Findling ${ }^{4}$, Bruno \\ Lanson $^{4}$, Bernard Fraisse ${ }^{5}$, Nicolas Marino ${ }^{6}$, and Benoit Gibert ${ }^{6}$ \\ ${ }^{1}$ Laboratoire de Géologie, Ecole Normale Supérieure, Paris \\ Sciences et Lettres, UMR8538, CNRS, Paris, France \\ ${ }^{2}$ Nordic Volcanological Center, Institute of Earth Sciences, \\ University of Iceland, 101 Reykjavík, Iceland \\ ${ }^{3}$ ÍSOR - Iceland GeoSurvey, Reykjavík, Iceland \\ ${ }^{4}$ Univ. Grenoble Alpes, Univ. Savoie Mont-Blanc, CNRS, IRD, \\ IFSTTAR, ISTerre, F-38000 Grenoble, France \\ ${ }^{5}$ Institut Charles Gerhardt Montpellier (ICGM), CNRS, Univ. \\ Montpellier, 34090 Montpellier, France \\ ${ }^{6}$ Géosciences Montpellier, University of Montpellier, France
}

August 5, 2019

1

2

3

4

\section{Abstract}

In volcanic environments, the presence of smectite may indicate recent hydrothermal circulations. Smectite is also responsible for enhanced rock electrical conductivity, as well as mechanical weakening. Therefore, 
quantifying smectite is important in geothermal exploration. Smectite identification requires X-ray diffraction (XRD) but quantification based on XRD is time-consuming and not always accurate. In the present study, we investigate the use of an optimized unbuffered Cation Exchange Capacity (CEC) measurement, by back-titration of the Coppertriethylenetetramine(II) "Cu-trien" molecule, to quantify the smectite content of altered volcanic rock samples. We establish that a satisfying trade-off between the instrument uncertainty and an independant systematic error is theoretically reached for a fraction of reactants consumed of about $30 \%$ at the end of the exchange reaction. We suggest a modification to classical protocols to fall in that range. Finally, we show that optimized CEC measurements by $\mathrm{Cu}$-trien are a direct measure of the smectite weight fraction in altered volcanic samples, with an average CEC of pure smectite of $90 \pm 5 \mathrm{meq} / 100 \mathrm{~g}$.

\section{Introduction}

One of the challenges of geothermal exploration at volcanoes is to detect the presence of active hydrothermal circulations in fractures. Geo-electrical and electromagnetic measurements are commonly used to this aim because electrical resistivity contrasts can delineate zones of intense hydrothermal activity (e.g. Árnason et al., 2000, Flóvenz et al., 2005. Flóvenz et al., 2012). Electrical resistivity of volcanic rocks is particularly sensitive to the presence of secondary "alteration" minerals, often witnesses of hydrothermal circulations in fractures, such as clay minerals. The distribution of clay minerals can provide estimates of the temperature distribution in volcanic or sedimentary systems where their formation is controlled by the geothermal gradient (Alt et al., 1986, Bourdelle et al., 2013. Kristmannsdóttir and Tómasson, 1978, Kristmannsdottir, 1979). In active hydrothermal systems, the formation of smectite is not only controlled 

43 Meller, 2014).

44

45

by the geothermal gradient, but also by the convective activity related to recent fault opening and causing boiling as well as chemical disequilibrium (Beaufort et al., 1995; Bril et al., 1996; Patrier et al., 1996). Compared to other clay minerals (e.g. illite, chlorite, kaolinite), smectite is much more conductive (e.g. Kaufhold et al., 2014 Kaufhold et al., 2015) and contributes significantly to the electrical conductivity of rocks, through Electrical Double Layer mechanisms (Flóvenz et al., 1985, Pezard, 1990, Revil and Glover, 1997; Waxman and Smits, 1968) and interfoliar conduction (Henry, 1997; Lévy et al., 2018; Maraqah et al., 1990). Smectite is also abundant in subduction zones (Hyndman et al., 1997) and in some major faults (Chester et al., 2013) and may play a role in the mechanical weakening of altered volcanic rocks (Heap et al., 2014, Kaufhold et al., 2012,

In order to study in the laboratory the influence of smectite on electrical conductivity and mecanical properties of volcanic rocks, the smectite content needs to be quantified first. Smectite content in drill-cuttings can also provide estimates of the porosity or permeability in a reservoir, by comparison with in-situ borehole resistivity logs (Flóvenz et al., 2005 Pezard, 1990; Revil et al., 1998, Rink and Schopper, 1974; Waxman and Smits, 1968).

The primary goal of our study is to provide geothermal industry with a simple method to quantify smectite content in hydrothermally altered volcanic rocks. Quantifying smectite in altered volcanic rocks is challenging because a large number of minerals often coexist in the same rock formation. Quantification of smectite by Rietveld-refinements of X-ray diffraction (XRD) patterns (e.g. Taut et al., 1998) is hampered when smectite-containing mixed layers coexist with smectite. Moreover, high-quality XRD scans are required for these quantifications, which can be time-consuming.

Due to its particular crystalline structure, smectite has a much larger Cation 
59 Exchange Capacity (CEC) than other clay minerals (Bouchet et al., 2000). This

6о CEC is mainly located in smectite interlayers (Dohrmann, 2006a; Lagaly, 1981,

${ }_{61}$ Vogt and Köster, 1978). Hower and Mowatt (1966) found a linear correlation

62 between the CEC and the smectite fraction in a series of illite-smectite samples.

63 Kaufhold and Dohrmann (2003) also observed that the CEC measured by back-

${ }_{64}$ titration of the Copper-triethylenetetramine(II) "Cu-trien" (Ammann et al.,

65 2005 Bergaya, 1997. Meier and Kahr, 1999) was proportional to the smectite

66 content in bentonites, qualitatively measured using the methylene blue method.

67 Altered volcanic rocks contain a larger variety of minerals than bentonite

68 or illite-smectite series, with often a large fraction of zeolites. Some zeolites,

69 such as clinoptilolite and heulandite, have a higher CEC than smectite, up to $300 \mathrm{meq} / 100 \mathrm{~g}$, thanks to their wide solid solution of extraframework cations

71 (Fridriksson et al., 2004). However, the CEC of clinoptilolite drops to $5 \mathrm{meq} / 100 \mathrm{~g}$

72 when measured by the Cu-trien method (Meier and Kahr, 1999), because the

73 channels where extraframework cations are located cannot expand, unlike smec-

74 tite interlayers, so that only small cations (smaller than $\mathrm{Cu}$-trien) can enter

75 clinoptilolite channels. Therefore, the $\mathrm{Cu}$-trien molecule appears to be adequate

76 to quantify the smectite content in altered volcanic rocks. Our study tests this

77 possibility by comparing CEC measurements to smectite quantifications based

78 on Rietveld-refinements of XRD patterns, for samples where smectite is the only

79 swelling clay mineral.

so Since altered volcanic rocks contain lower and more variable smectite content

$\mathbf{8 1}$ than bentonite or illite-smectite series, the solid/solution ratio needs to be op-

82 timized for each sample, in order to minimize both the instrument uncertainty

83 and systematic biases. The need for optimization of the reactants (exchange

84 solution and sample) proportion was first addressed by Orsini and Remy (1976)

s5 for CEC measurements with the Cobalti-hexamine molecule, "Co-hex", on large 
86

87

88

masses of soil samples. Orsini and Remy (1976) pointed out that the exchange between Co-hex and soil samples could be considered as total only when the initial quantity of Co-hex was at least three times superior to the CEC. Yet, beyond eight times, the accuracy of the measurements would significantly decrease. Based on these observations, the authors recommended to carry out experiments where the initial ratio between Co-hex and rock sample (expressed in CEC units) represents $30 \%$ to $80 \%$ of the CEC, or equivalently where the fraction of Co-hex consumed during the experiments ranges between $15 \%$ and $30 \%$. Further development of the Co-hex back-titration method (Cieselski et al., 1997. Ciesielski et al., 1997) allows extending the interval of Co-hex consumed to $5 \%-35 \%$. The need to optimize the solid/solution ratio by adjusting the initial mass of sample, for samples having a wide range of CEC values, is also discussed for the Cu-trien method by Dohrmann and Kaufhold (2009) and by Dohrmann (2006b) for the similar Ag-thiourea method.

Our study investigates the theoretical grounds for the observations of Dohrmann and Kaufhold (2009) and the ranges suggested by Orsini and Remy (1976) and Ciesielski et al. (1997) and presents a simple method for quantifying the smectite content of altered volcanic rocks through optimized CEC measurements using the $\mathrm{Cu}$-trien exchange complex.

\section{Materials and Methods}

\subsection{Rock samples}

Thirty-eight samples from the Krafla high-temperature geothermal area are used in this study. Core samples are collected from four cored boreholes (KH1, KH3, KH5 and KH6) at varying depths. They represent a variety of lithologies and secondary minerals (Table 1). Cylindrical plugs $(2-3 \mathrm{~cm}$ long and $2.5 \mathrm{~cm}$ diame- 
111 ter) are prepared from the original core samples for petrophysical measurements, 112 presented by Lévy et al. (2018). From the lateral faces of the plugs, thin sec113 tions and powders are prepared. Ten samples are used for optimization of CEC 114 measurements, 24 samples for comparison between quantitative XRD analysis 115 and CEC, 15 samples for chemical analysis by Electron Probe Micro Analy116 sis (EPMA) and four samples for ICP analyses of exchangeable cations. Some 117 samples are used for more than one type of analysis (Table 1). 


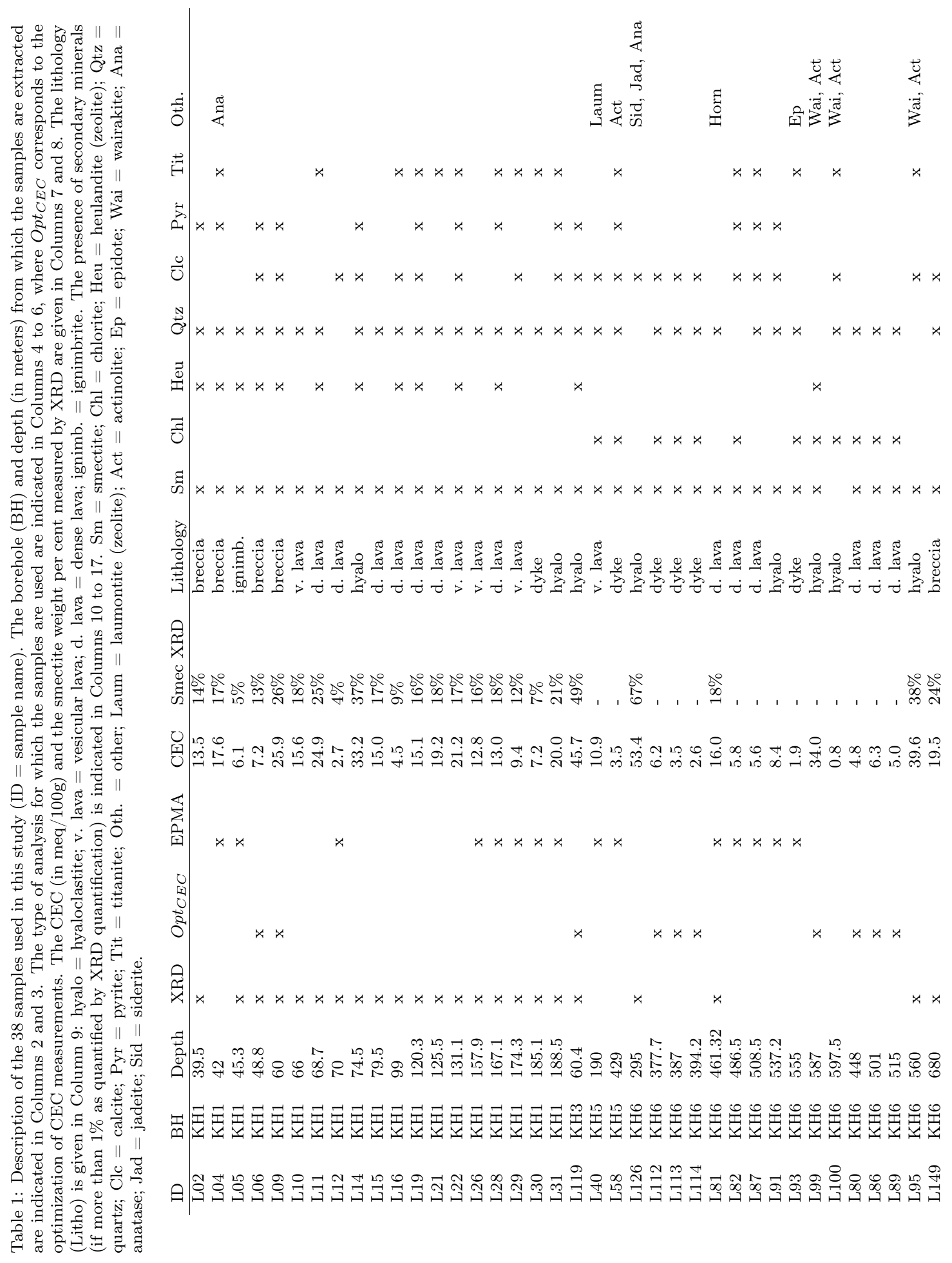


A first set of powders is used for the analysis of CEC uncertainty, carried out on 88 samples but presented here for 10 relevant samples. This set of powders is roughly grained to powder size, without any size control.

A second set of powders is used for XRD scans and associated mineral quantification by Rietveld-refinements. Powders from the first set are further ground for 10 minutes in ethanol, using an automatic grinder Retsch RM 200, dried and sieved before being prepared as randomly oriented mounts. For each sample, the exact same powder is used later on for independent CEC measurements that are later compared to XRD mineral quantification.

\subsection{Mineral quantification by X-ray Diffraction}

The powders are front-loaded onto the sample holder, using a razor blade to smooth out the surface, in order to minimize preferred orientation (PO) and shift of diffraction peaks (Bish and Reynolds, 1989). An example of PO issues when the sample is back-loaded is shown in Appendix A. The XRD scans are carried out over the range $4-75^{\circ} 2 \theta\left(4-65^{\circ} 2 \theta\right.$ for a few samples) with a Philips X'Pert Pro (radiation $\mathrm{Cu}-\mathrm{K} \alpha$; $45 \mathrm{kV} ; 30 \mathrm{~mA}$; step size $0.0167^{\circ}$; time per step 240 s; X'Celerator Scientific high-speed detector; $240 \mathrm{~mm}$ goniometer radius). The XRD patterns are analyzed quantitatively with the Rietveld program BGMN and the Profex user-interface (Doebelin and Kleeberg, 2015 Taut et al., 1998). The following mineral phases are considered for the refinements: forsterite, labradorite, bytownite, orthoclase, albite, augite, diopside, kanoite, smectitetri, zeolite (heulandite, clinoptilolite, philippsite, dachiardite, laumontite, analcime), pyrite, ilmenite, titano-magnetite, jadeite, siderite, hematite, maghemite, anatase, titanite, schorl, chlorite, calcite, quartz, wairakite, prehnite, epidote, actinolite, garnet, grossular. Two examples of refinements are shown, in Figure

1 for a sample containing smectite as the only clay mineral and in Figure 2 for 
144 a sample containing smectite, chlorite, and most likely chlorite-smectite.

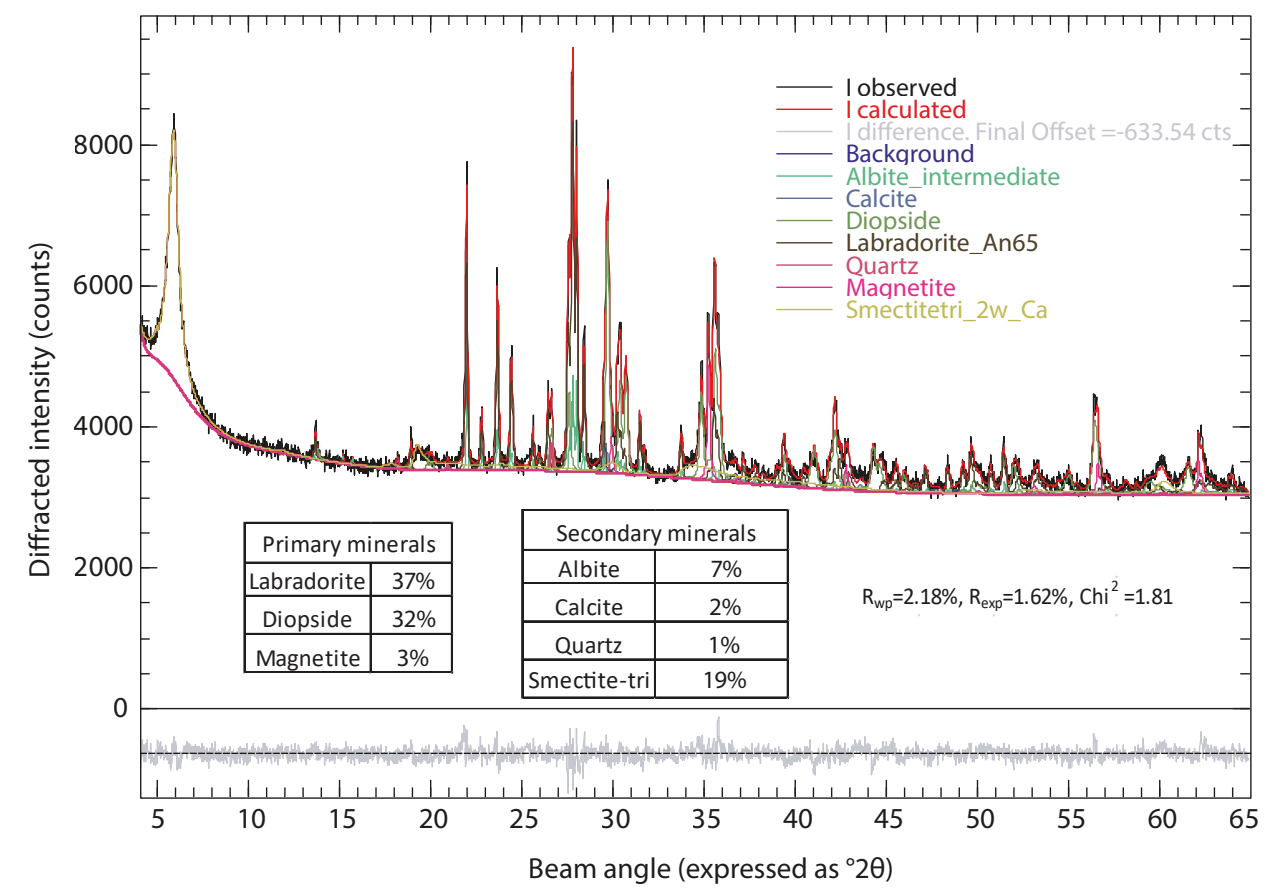

Figure 1: XRD quantitative analysis, using the BGMN software, for sample L15 containing smectite as the only clay mineral. The resulting mineral percentages and fit quality are indicated on the graph.

$145 \quad$ In samples containing a mixture of disordered clay phases (such as smectite

146 and smectite-containing mixed layers and/or disordered 1:1 minerals), smectite content is difficult to quantify accurately by Rietveld-refinements, because of the strong correlation between parameters, including background (e.g. Raven and Self, 2017). XRD patterns of samples containing both smectite and chlorite can be fitted (Figure 2 but the software adjusts both the chemical compo151 sition of chlorite and the relative quantity of chlorite and smectite to fit the relative intensities of the $\mathrm{d}(001)$ peak at $14-15 \AA$ and the $\mathrm{d}(002)$ peak at $7.2 \AA$.

153 This results in the non-uniqueness of the model parameters related to chlorite ${ }_{154}$ chemistry and smectite and chlorite quantities. The chemistry of chlorite can be 
constrained (especially the relative abundance of $\mathrm{Fe}$ and $\mathrm{Mg}$ ), based on independent chemical analyses, but this requires a large number of EPMA on polished thin sections, to obtain a representative chemical composition of chlorite for the sample, which is time-consuming and expensive. Moreover, assuming that the chemistry of chlorite can be properly constrained, the combined presence of smectite and chlorite often implies the presence of a chlorite-smectite phase. This chlorite-smectite phase also contributes to the $\mathrm{d}(001)$ peak at $14-15 \AA$ and its contribution can hardly be discriminated from that of pure smectite. As a result, the fitted amount of "smectite" corresponds in reality to a quantity of smectite + chlorite-smectite. Since only the quantity of smectite layers matters for the comparison to the CEC, not the quantitiy "smectite+ chlorite-smectite", this quantification is not appropriate. Therefore, only smectite quantifications for samples containing no other clay phase are used in this study for further comparison to CEC measurements.

Special studies are necessary to determine the exact type of smectite present in each sample, especially regarding the type of interlayer cation $\left(\mathrm{Ca}^{2+}\right.$ or $\left.\mathrm{Na}^{+}\right)$, the number of water layers surrounding interlayer cations and the tri- or dioctahedral character. The tri- or dioctahedral character mainly influences the $\mathrm{d}(060)$ diffraction peaks, at high angles, which have a lower intensity and are overlapping with other minerals such as quartz. These high-angle peaks only negligibly affect (if at all) the refinement. On the other hand, low-angle peaks, especially the $\mathrm{d}(001)$ around $14-15 \AA$, which is influenced by the composition of the interlayer space both in terms of cation and water layer, significantly affect the refinement. Therefore, the patterns are fitted with two different types of smectite phases: a phase corresponding to a "tri-octahedral smectite with interfoliar spaces filled with Ca, accompanied by two water layers", and another tri-octahedral smectite "saponite" with more flexible interlayer distance (see de- 


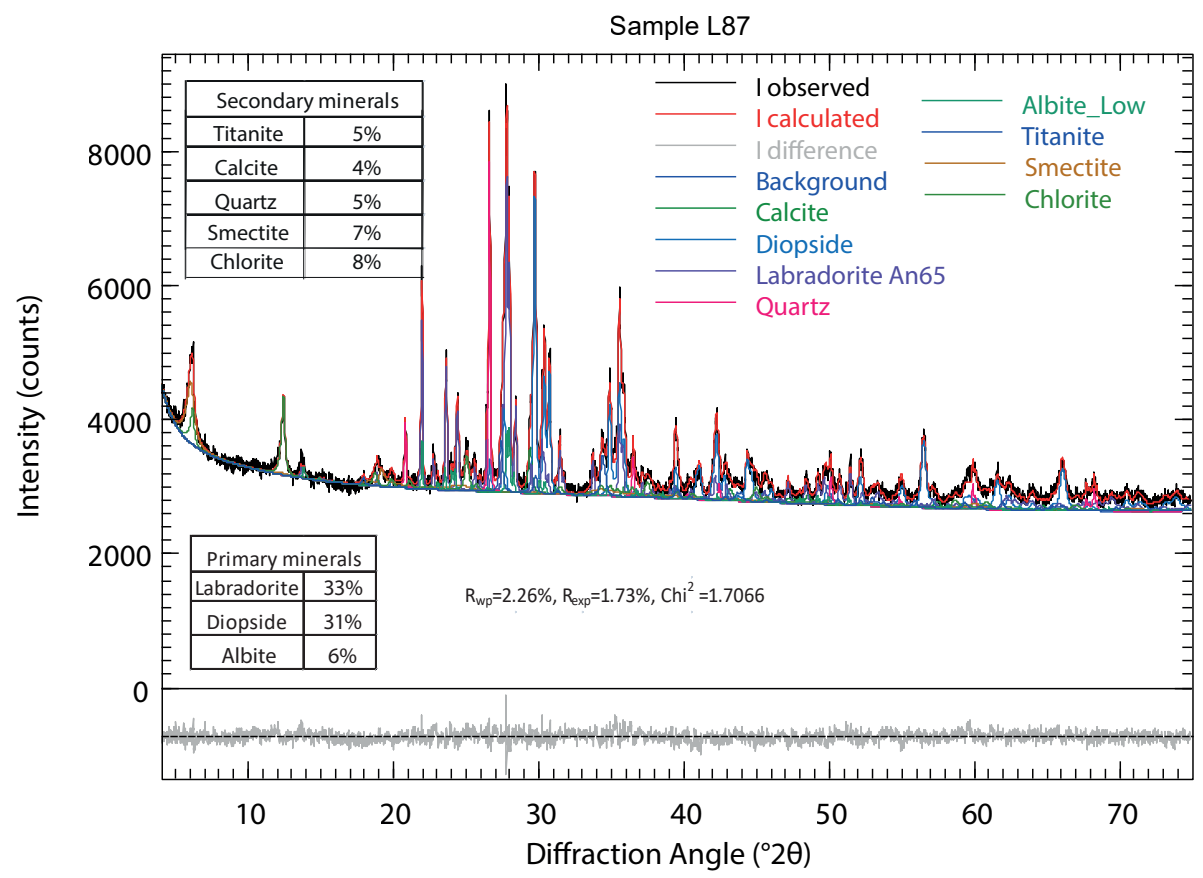

Figure 2: XRD quantitative analysis, using the BGMN software, for a sample containing smectite, chlorite and mixed layer chlorite-smectite.

tailed structure files in Appendix B). An uncertainty on the smectite content is calculated based on the discrepancy between the two fits. For the other minerals, the uncertainty is calculated based on the variance of the model parameters given by the software.

\subsection{CEC determination}

The CEC of altered volcanic rocks is measured by back-titration of the Coppertriethylenetetramine (Cu-trien) molecule, as in the original protocol designed by

Meier and Kahr (1999) to measure the CEC of pure clay samples. This molecule

is also used, for example, by Kaufhold and Dohrmann (2003) to measure the CEC of bentonites.

First, the sample is weighted in a beaker and then $50 \mathrm{ml}$ of deionized water, measured with a volumetric flask, are added into the beaker. The few remaining 
water drops in the volumetric flask, after adding water to the beaker, represent an average of $0.6 \pm 0.2$. In order to reduce the uncertainty on the water volume, we measure the exact mass of water added to the beaker and adjust it by weight as close as possible to $50.00 \mathrm{~g}$. Without this weight adjustment and measurement, the volume of water added is $49.4 \pm 0.2 \mathrm{ml}$. The beaker containing the water-rock mixture is then left in an ultrasonic bath for 5 minutes. Next, $10 \mathrm{ml}$ of $\mathrm{Cu}$-trien at about $1.10^{-2} \mathrm{~mol} / \mathrm{L}$ are added with a $5 \mathrm{ml}$ pipette (two steps). Details about the preparation and characterization of the exchange $\mathrm{Cu}$-trien solution at $1.10^{-2} \mathrm{~mol} / \mathrm{L}$ are given in Appendix C. The exchange is considered complete after 5 minutes of magnetic stirring. Since most of the exchange is expected to occur within interlayer spaces of swelling clay minerals (smectite), 5 minutes are considered sufficient. A test, carried out on sample L126, indicates that the difference in exchange yield after 5 and 60 minutes is within the instrument uncertainty, and thus not significant (see more details in Appendix C). If the CEC of higher charge clay minerals (e.g. vermiculite) were investigated, longer contact times might be needed (Von Reichenbach, 1968).

After the exchange reaction is completed, solid and liquid are separated by centrifugation. Finally, the absorbance of the supernatant solution is measured by a spectrophotometer at $578 \mathrm{~nm}$. The absorbance of the $\mathrm{Cu}$-trien solution before exchange, prepared independently by mixing $50 \mathrm{ml}$ of deionized water and $10 \mathrm{ml}$ of $\mathrm{Cu}$-trien at $1.10^{-2} \mathrm{~mol} / \mathrm{L}$, is also measured. The CEC (in meq/100g) is then calculated with Equation 1 .

$$
C E C_{l a b}=\frac{2\left(C_{i}-C_{f}\right) V}{m}
$$

where $V$ is the total volume of the solution $(60 \mathrm{ml}), m$ is the rock mass in mg and $C_{i}$ and $C_{f}$ are the Cu-trien concentrations in the initial and final solutions, respectively, in mol/L. $C_{i}$ and $C_{f}$ are calculated based on the absorbance 
measurements and the calibration curve presented in Appendix C.

The rock mass suggested by Meier and Kahr (1999) is $200 \mathrm{mg}$ but is a key parameter to be adjusted: $m$ varies between 100 and $1000 \mathrm{mg}$ in our experiments (see e.g. Dohrmann, 2006b; Dohrmann and Kaufhold, 2009). If the CEC can be approximately estimated, e.g. thanks to XRD measurements and rapid evaluation of the $\mathrm{d}(001)$ peak of smectite at $14-15 \AA$, the mass of rock is chosen accordingly. If the $\mathrm{d}(001)$ is intense compared to other peaks and no $\mathrm{d}(002)$ at $7.2 \AA$ is observed, meaning that there is little to no chlorite or chlorite-smectite, then $200 \mathrm{mg}$ of rock sample are considered appropriate. If chlorite or chloritesmectite are present in significant amount (e.g. if $\mathrm{d}(002)$ more intense than $\mathrm{d}(001)), 400 \mathrm{mg}$ are used. If the $\mathrm{d}(001)$ peak is absent or small compared to the background, then $1000 \mathrm{mg}$ are used. If no assumption on the smectite amount can be made priori to CEC measurement, then a first measurement with $200 \mathrm{mg}$ is carried out. After the first CEC measurement, the mass of rock is adjusted accordingly to the result for the next measurement. At least two measurements with the same rock mass are carried out for each sample.

The protocol and equation presented here-above uses rock masses as dried at room temperature. The water content is determined independently by weighting a given mass of sample at room temperature and after drying in an oven at $105^{\circ} \mathrm{C}$. Water content measurements, as well as corresponding correction of CEC values, are presented in Appendix D.

\subsection{Analysis of exchangeable cations in smectite}

Chemical analyses of clay minerals are carried out on 15 polished thin sections at Géosciences Montpellier, using a CAMECA SX100 electron microprobe (22 $\mathrm{keV}, 10 \mathrm{nA})$. The 15 samples used for these measurements are indicated in Table . 
Inductively Coupled Plasma Atomic Emission Spectroscopy (ICP-AES) analyses are carried out at ÍSOR to characterize the main cations exchanged after reaction with $\mathrm{Cu}$-trien. Magnesium, calcium and sodium concentrations are measured at the wavelengths $279.079,373.690$ and $589.592 \mathrm{~nm}$, respectively. The exchangeable cations of four samples are investigated by this method: L119, L96, 31 and L99. Solutions are analysed at three steps of the reaction for each sample: after mixing rock and water, after ultra-sonic bath and after exchange with $\mathrm{Cu}$-trien. This allows not taking into account cations coming from basic water-rock interaction (e.g. dissolution of glass or minerals).

\section{Results and Discussion}

\subsection{Estimation of the laboratory uncertainty}

We calculate the total uncertainty on the CEC measurements, $u_{t o t}$, by taking into account measurement dispersion, $u_{\text {disp }}$, and instrument resolution, $u_{i n s t r}$.

The general formula, based on the rule of error propagation by Taylor expansions, is presented in Equation 2 (e.g. Joint Committee for Guides in Metrology (JCGM), 2008; Ku, 1966).

$$
\begin{array}{r}
u_{\text {tot }}(C E C)=\sqrt{u_{\text {instr }}(C E C)^{2}+u_{\text {disp }}(C E C)^{2}} \\
u_{\text {disp }}(C E C)=\sqrt{\frac{1}{n(n-1)} \sum_{i=1}^{n}\left(C E C_{i}-C E C_{\text {avg }}\right)^{2}} \\
\frac{u_{\text {instr }}(C E C)}{C E C}=\sqrt{\left(\frac{u(V)}{V}\right)^{2}+\left(\frac{u(m)}{m}\right)^{2}+\left(\frac{u\left(C_{i}-C_{f}\right)}{C_{i}-C_{f}}\right)^{2}}
\end{array}
$$

where $n$ is the number of measurements for each sample, usually two or three, and $C E C_{\text {avg }}$ the average of the $n$ measurements. $\mathrm{u}(\mathrm{V})$ and $\mathrm{u}(\mathrm{m})$ are the uncer- 
tainties on volume and mass, respectively, and $\mathrm{u}\left(C_{i}-C_{f}\right)$ the uncertainty on the difference between initial and final concentrations. We explain below how these three terms are calculated.

The uncertainty on rock weighting is estimated to $u(m)=0.5 \mathrm{mg}$, based on the variations of the last digit of the scale.

The uncertainty on the total volume $(60 \mathrm{ml})$ measurement is calculated by propagating the uncertainty of the three measured volumes (see Equation 3).

$$
\begin{aligned}
V & =V_{\text {wat }}+2 V_{\text {pip }} \\
u(V) & =\sqrt{u\left(V_{w a t}\right)^{2}+2 u\left(V_{\text {pip }}\right)^{2}}
\end{aligned}
$$

where $u\left(V_{\text {wat }}\right)$ is the uncertainty on the $50 \mathrm{~mL}$ of water and $u\left(V_{p i p}\right)$ is the uncertainty on the $5 \mathrm{ml}$ of $\mathrm{Cu}$-trien (measured twice with a $5 \mathrm{ml}$ micropipette to obtain $10 \mathrm{ml}) \cdot u\left(V_{\text {pip }}\right)$ is estimated to $0.02 \mathrm{~mL}$ (by pipetting step). $u\left(V_{\text {wat }}\right)$ is reduced from 0.20 to $0.01 \mathrm{ml}$ when the exact mass of water added to the rock is measured. This results in a total volume uncertainty $u(V)=0.03 \mathrm{ml}$, while it amounts to $u(V)=0.20 \mathrm{ml}$ when the water is direcly added from the volumetric flask without further verification.

The calculation of the uncertainty on the concentration difference is presented in Equation 4

$$
\begin{aligned}
A_{i}-A_{f} & =L\left(C_{i}-C_{f}\right) \\
\left(\frac{u\left(C_{i}-C_{f}\right)}{C_{i}-C_{f}}\right)^{2} & =\left(\frac{u\left(A_{i}-A_{f}\right)}{A_{i}-A_{f}}\right)^{2}+\left(\frac{u(L)}{L}\right)^{2} \\
& =\frac{u\left(A_{i}\right)^{2}+u\left(A_{f}\right)^{2}}{\left(A_{i}-A_{f}\right)^{2}}+\left(\frac{u(L)}{L}\right)^{2}
\end{aligned}
$$

5 where $A_{i}$ and $A_{f}$ are the initial and final absorbance, respectively, and $u\left(A_{i}\right)=$ $u\left(A_{f}\right)$ their respective uncertainty. $L$ is the slope of the calibration curve (ab- 
286

sorbance versus concentration, see Appendix $\mathrm{C})$ and $u(L)$ is calculated using the error propagation rule presented above, with an expression of $L$ based on the two extreme calibration points and their respective uncertainty (Joint Committee for Guides in Metrology (JCGM), 2008).

The uncertainty on the absorbance measured by the spectrophotometer is considered to be 0.001 , based on the dispersion observed for repeated measurements of the same solution, as well as the spectrophotometer resolution provided by the manufacturer.

The total instrument relative uncertainty is given by Equation 5 .

$$
\frac{u_{\text {instr }}(C E C)}{C E C}=\sqrt{\frac{u\left(V_{\text {flask }}\right)^{2}+2 u\left(V_{\text {pip }}\right)^{2}}{V^{2}}+\frac{u(m)^{2}}{m^{2}}+\frac{2 u\left(A_{i}\right)^{2}}{\left(A_{i}-A_{f}\right)^{2}}+\frac{u(L)^{2}}{L^{2}}}
$$

\subsection{Increasing the rock mass decreases the laboratory un- certainty for low-CEC rocks}

Based on Equation 5, we calculate, for six samples, the instrument uncertainty of CEC measurements using two different initial rock masses and the same initial $\mathrm{Cu}$-trien solution. We show that the relative uncertainty decreases from up to $70 \%$ to less than $5 \%$ when increasing the rock mass from the $200 \mathrm{mg}$, as recommendend for example by Meier and Kahr (1999), to $1000 \mathrm{mg}$ (Figure 3). In the present case, increasing the rock mass from 200 to $1000 \mathrm{mg}$ increases the fraction of $\mathrm{Cu}$-trien consumed from less than 1\% to about 13\% (Sample L114 in Figure 3].

Figure 3 shows that the instrument uncertainty exponentially decreases with the fraction of $\mathrm{Cu}$-trien consumed. This is consistent with Equation 5, where the denominator $\left(A_{i}-A_{f}\right)^{2}$ controls the overall value of $\mathrm{u}(\mathrm{CEC})$ because $\frac{u(V)}{V}$ 


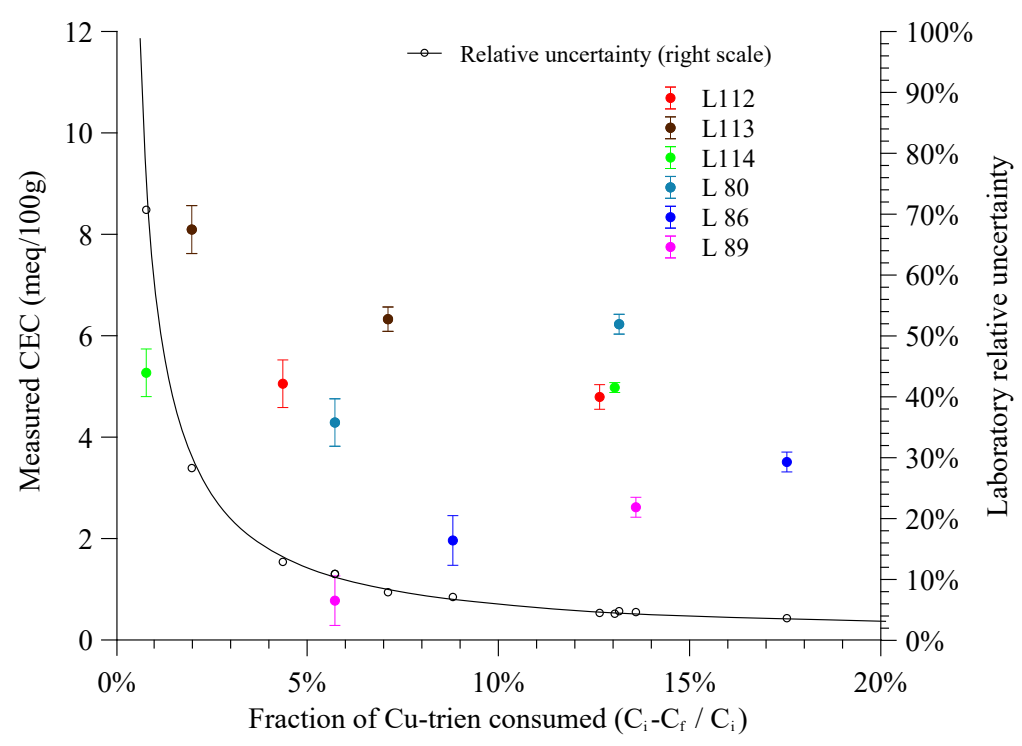

Figure 3: Measured CEC and relative laboratory (instrument) uncertainty as a function of the fraction of Cu-trien consumed. The circles with error bars correspond to the measured CEC (left axis) and the stars to the uncertainty, as calculated in Equation 5 (right axis). An increased fraction corresponds to an increased mass of rock initially present. Each color corresponds to one sample. The six samples used in this figure have a CEC lower than 5 meq/100g. Error bars (both positive and negative) are calculated as the product of the measured CEC by the relative uncertainty.

300 and $\frac{u(m)}{m}$ are very small compared to the third term. This is particularly true

301 for samples with CEC lower than 5 meq/100g, i.e. with low smectite content.

302 This effect is due to the limited number of digits, which can be read on the spectrophotometer (only three digits, with values always $\leq 1$ ).

\subsection{Increasing the rock mass decreases the yield of the exchange reaction for high-CEC rocks}

For high-CEC samples, we observe that the measured CEC can decrease by up to $50 \%$ when the rock mass is increased, for fixed initial volume and concentration of Cu-trien (Figure 4). Dohrmann and Kaufhold (2009) suggest that an unsuitably small solution/solid ratio may result in a reduced selectivity of the index cation (Cu-trien in their case) and thus in an incomplete exchange of 
311 interlayer cations. A similar observation is mentioned in Cieselski et al. (1997)

312 for CEC measured by the Co-hex index cation and attributed to a reduced

313 yield of the exchange reaction when the fraction of Co-hex consumed exceeds a

314 threshold.

315 Here, we investigate the mathematical expression of these empirical observa-

316 tions, in order to predict the yield of the exchange reaction between $\mathrm{Cu}$-trien and

s17 the rock sample and determine an acceptable threshold of $\mathrm{Cu}$-trien consumption

318 at the end of the reaction. The yield of the exchange reaction is taken as the rel-

319 ative difference between the apparent measured CEC, $C E C_{a p p}=C E C_{l a b}$, and
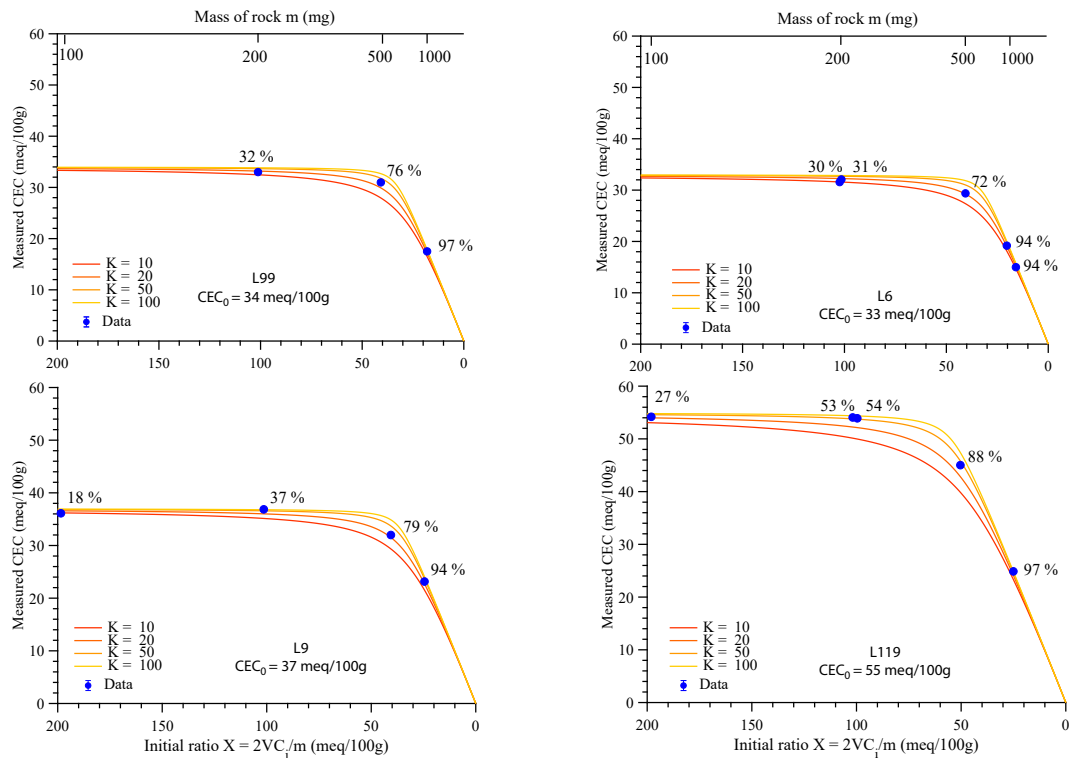

Figure 4: Measured CEC with different initial ratios of reactants (Cu-trien and rocks) for four samples (blue filled circles): L99, L9, L6 and L119. The initial concentration of $\mathrm{Cu}$-trien is about constant $\left((1.6 \pm 0.1) \cdot 10^{-3} \mathrm{~mol} / \mathrm{L}\right)$ but the mass of rock varies between 100 and $1000 \mathrm{mg}$ (top x-axes). The fraction of $\mathrm{Cu}$-trien consumed at the end of the reaction is marked aside each measurement. The laboratory (instrument) uncertainty is smaller than the symbols. The model predictions for four values of the thermodynamic constant $K$ are also displayed as plain lines with a warm colorscale. The values of $K$ are chosen on a trial-error basis, assuming $K \geq 1$. The value of $C E C_{0}$ used for these predictions is marked together with the name of the sample, and corresponds to the measured CEC for the highest initial ratios. The values of $C E C_{0}$ may differ from the values given in Table 1 because a different set of powder is used for these measurements than for the measurements related to the correlation with XRD refinements. 
between the $\mathrm{Cu}$-trien(II) cations and $\mathrm{Ca}^{2+}$ cations filling the exchange sites in the rock samples. According to chemical analyses of the smectite grains carried out by EPMA, there is at least twice as much $\mathrm{Ca}^{2+}$ filling the interlayer spaces than $\mathrm{Na}^{+}$. There is an overall abundance of $\mathrm{Mg}^{2+}$ in the structural formula of these saponites but EPMA does not allow differentiating $M g^{2+}$ in the crystal lattice from $\mathrm{Mg}^{2+}$ in the interlayer space. The concentration of $\mathrm{Mg}$, $\mathrm{Ca}$ and $\mathrm{Na}$, measured by ICP in the solutions after exchange with $\mathrm{Cu}$-trien for four samples, indicate that no $\mathrm{Na}$ has been exchanged and that exchanged-Ca and exchanged-Mg represent $72-94 \%$ and $8-13 \%$ of the total cation exchange capacity, respectively. These two types of result confirm that bivalent cations represent the majority of interlayer cations and the exchange ratio with $\mathrm{Cu}$ trien(II) will be mostly 1:1 (Figure 5).

The chemical exchange reaction, considering a majority of $\mathrm{Ca}^{2+}$ in the initial state, is written in Equation 6 .

$$
\mathrm{Cu}_{\mathrm{aq}}+\mathrm{Ca}_{\mathrm{ads}} \rightleftharpoons \mathrm{Ca}_{\mathrm{aq}}+\mathrm{Cu}_{\mathrm{ads}}
$$

The thermodynamic constant $K$ of this exchange reaction is defined in Equation 7

$$
K=\frac{X_{C u, e q} a_{C a, e q}}{X_{C a, e q} a_{C u, e q}}
$$

where the subscript "eq" indicates that a chemical equilibrium is reached. $X_{C u, e q}$ and $X_{C a, e q}$ are the dimensionless chemical activities of cations $\mathrm{Cu}$-trien(II) and $\mathrm{Ca}^{2+}$ filling sites in the rock at the end of the exchange reaction, respectively, and $a_{C u, e q}$ and $a_{C a, e q}$ are the dimensionless chemical activities of cations $\mathrm{Cu}-$ trien(II) and $\mathrm{Ca}^{2+}$ in the aqueous solution at the end of the exchange reaction, respectively. Chemical activities are defined in Equation 8, where the subscript "eq" is removed for clarity purposes, but we assume the thermodynamic equi- 


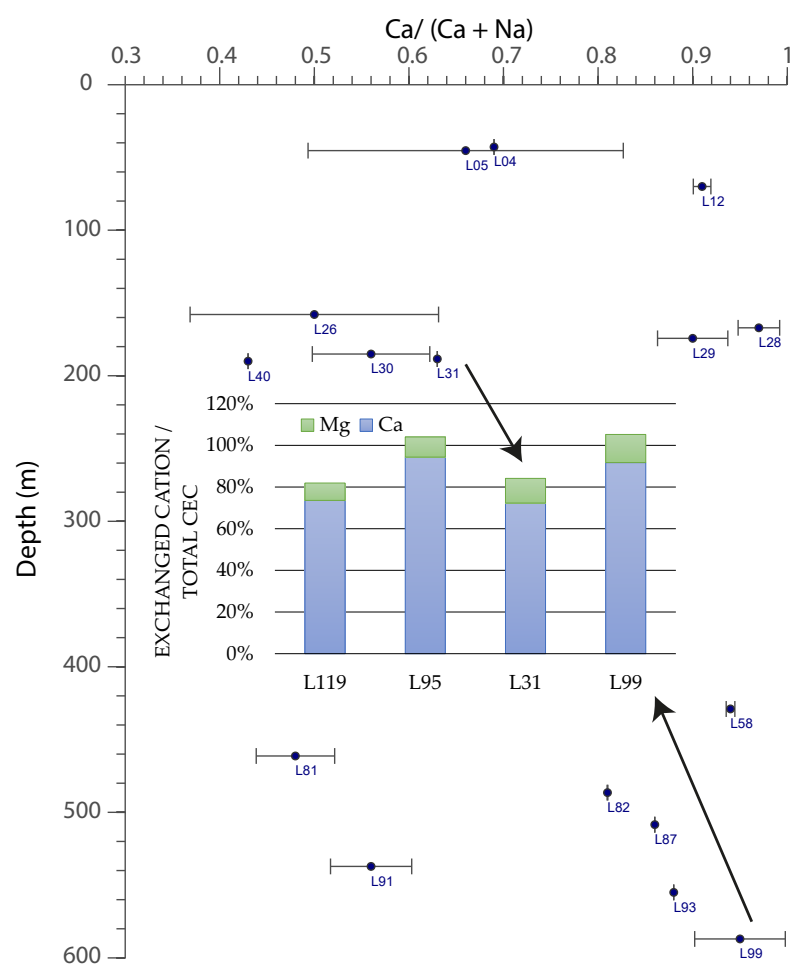

Figure 5: Number of exchangeable Ca-ions compared, to Na-ion and Mg-ion in the interlayer spaces of smectites. The relative number of exchangeable Ca versus $\mathrm{Na}$ is shown as a function of sampling depth. Sixteen samples, where chemical analyses by electron probe are carried out, are reported on this figure: L04 to L31 from KH1, L40-L58 from KH5 and L81-L99 from KH6. The error bar indicates the range of values found for the different smectite grains measured in each thin section. The histogram at the center shows the distribution of exchangeable $\mathrm{Mg}$ and Ca in four samples, as measured by ICP in the exchange solutions after reaction with $\mathrm{Cu}$-trien. The sodium concentration in the solutions after exchange is not significantly higher than in the solutions before exchange (both before and after ultra-sonic bath) for any of the samples. Both types of measurements are available for two samples (L31 and L99).

346 librium is reached.

$$
\left\{\begin{array}{l}
a_{C u}=[C u]_{a q} \\
a_{C a}=[C a]_{a q} \\
X_{C u}=\frac{m e q(C u)}{m C E C_{0}} \\
X_{C a}=\frac{m e q(C a)}{m C E C_{0}}
\end{array}\right.
$$


349

350

$$
\left\{\begin{array}{l}
{[C u]_{a q}=C_{f}} \\
{[C a]_{a q}=C_{i}-C_{f}} \\
m e q(C u)=m C E C_{a p p} \\
m e q(C a)=m\left(C E C_{0}-C E C_{a p p}\right)
\end{array}\right.
$$

357 Combining Equations 7, 8 and 9, the thermodynamic constant, $K$, can be 358 written as in Equation 10

$$
K=\frac{m e q(C u)}{m e q(C a)} \times \frac{C_{i}-C_{f}}{C_{f}}=\frac{C E C_{a p p}}{C E C_{0}-C E C_{a p p}} \times \frac{C_{i}-C_{f}}{C_{f}}
$$

Given that $C E C_{a p p}=C E C_{l a b}$ and following Equations 1, 9 and 10, $m e q(C u)$ and $m e q(\mathrm{Ca})$ can also be written, as in Equation 11 .

$$
\left\{\begin{array}{l}
m e q(C u)=2 V\left(C_{i}-C_{f}\right) \\
m e q(C a)=\frac{m e q(C u)\left(C_{i}-C_{f}\right)}{K C_{f}}=\frac{2 V\left(C_{i}-C_{f}\right)^{2}}{K C_{f}}
\end{array}\right.
$$

Assuming that all exchange sites are filled with either $\mathrm{Cu}$-trien(II) or $\mathrm{Ca}^{2+}$ 
at the end of the reaction, the total $\mathrm{CEC}, C E C_{0}$, is described in Equation 12 .

$$
\begin{aligned}
C E C_{0} m & =m e q(C u)+m e q(C a) \\
\Longleftrightarrow C E C_{0} & =\frac{2\left(C_{i}-C_{f}\right) V}{m}\left(1+\frac{\left(C_{i}-C_{f}\right)}{K C_{f}}\right) \\
\Longleftrightarrow K C_{f} C E C_{0} & =C E C_{a p p}\left(K C_{f}+C_{i}-C_{f}\right) \\
& =C E C_{a p p}\left[(K-1) C_{f}+C_{i}\right] \\
\Longleftrightarrow C_{f} & =C_{i} \times \frac{C E C_{a p p}}{K C E C_{0}+(1-K) C E C_{a p p}}
\end{aligned}
$$

By writing $C_{f}$ as a function of $C_{i}, m, V$ and $C E C_{a} p p$ (Equation 1), Equation 12 gives Equation 13.

$$
\begin{aligned}
C_{i}-\frac{m C E C_{a p p}}{2 V} & =C_{i} \times \frac{C E C_{a p p}}{K C E C_{0}+(1-K) C E C_{a p p}} \\
\Longleftrightarrow\left(K C E C_{0}+(1-K) C E C_{a p p}\right) & \times\left(2 V C_{i}-m C E C_{a p p}\right) \\
& =2 V C_{i} C E C_{a p p}
\end{aligned}
$$

Equation 13 can be re-written as a second-order equation of the variable $Y=C E C_{a p p}$ (Equation 14 .

$$
\begin{aligned}
& (1-K) Y^{2}+\left(K C E C_{0}+\frac{2 V K C_{i}}{m}\right) Y-\frac{2 V K C_{i} C E C_{0}}{m}=0 \\
& \Longleftrightarrow a Y^{2}+b Y+c=0\left\{\begin{array}{l}
a=1-K<0 \\
b=K C E C_{0}+\frac{2 V K C_{i}}{m} \\
c=-\frac{2 V K C_{i} C E C_{0}}{m} \\
\Delta=b^{2}-4 a c
\end{array}\right.
\end{aligned}
$$

with $a<0$ because $K>1$ (otherwise no exchange would occur). By solving the second-order equation (14) and keeping only the positive solution (which remains positive even if $K<1$ ), we obtain an explicit function for $C E C_{a p p}$ 
(Equation 15).

$$
\begin{aligned}
Y=C E C_{a p p} & =\frac{-b+\sqrt{\Delta}}{2 a} \\
& =\frac{-(\alpha+X)+\sqrt{(\alpha+X)^{2}+2 \alpha \beta X}}{\beta}\left\{\begin{array}{l}
X=2 V \frac{C_{i}}{m} \\
\alpha=C E C_{0} \\
\beta=2 \frac{1-K}{K}<0
\end{array}\right.
\end{aligned}
$$

The function of $X$ presented in Equation 15 increases monotoneously with $X$ and reaches asymptotically the value of $C E C_{0}$. Since $X$ is inversely proportional to $m$, the sequence of equations presented here predicts that an increase of rock mass (all other things being equal) will increase the difference between $C E C_{a p p}$ and its asymptote $C E C_{0}$, which is equivalent to reducing the yield of the exchange reaction.

This model based on simple assumptions predicts the observations of Dohrmann and Kaufhold (2009) and Cieselski et al. (1997) that the sample mass is the determining factor for optimum precision of the CEC and exchangeable cations, if the same volume of solution is used. The function presented in Equation 15 can also predict our experimental observations on samples with large smectite volume, provided that $C E C_{0}$ is chosen accordingly (Figure 4). Values of $K$ in the range 10-100 are consistent with the observations but the value of $K$ does not affect much the predictions. Given the limited sensitivity of the model to the value of $K$, we do not attempt here to evaluate precisely this constan. We only suggest that the range $20-50$ is appropriate to describe the reaction taking place in the samples shown in Figure 4. In reality, $K$ depends not only on the exchanged cation but also on the type of minerals and of sites involved in the exchange (Tertre, 2014, Reinoso-Maset et al., 2012 Durrant et al., 2018, Robin et al., 2015 Robin et al., 2017). 


\subsection{Optimization of the CEC measurements}

Equations 16 and 17 describe the "partial exchange" systematic error and "instrument" uncertainty, as a function of the fraction $x=\frac{C_{i}-C_{f}}{C_{i}}$ of $\mathrm{Cu}$-trien consumed after the reaction, based on Equations 12 and 5 respectively.

$$
\begin{aligned}
E r r_{\text {partial }} & =\frac{C E C_{0}-C E C_{a p p}}{C E C_{a p p}}=\frac{\left(C_{i}-C_{f}\right)}{K C_{f}}=\frac{x}{K(1-x)} \\
\frac{u_{\text {instr }}(C E C)}{C E C} & =\sqrt{\frac{u\left(V_{\text {flask }}\right)^{2}+2 u\left(V_{\text {pip }}\right)^{2}}{V^{2}}+\frac{u(m)^{2}}{m^{2}}+\frac{2 u\left(A_{i}\right)^{2}}{\left(A_{i}-A_{f}\right)^{2}}+\frac{u(L)^{2}}{L^{2}}} \\
& =\sqrt{\frac{u\left(V_{\text {flask }}\right)^{2}+2 u\left(V_{\text {pip }}\right)^{2}}{V^{2}}+\frac{u(m)^{2}}{m^{2}}+\frac{2 u\left(A_{i}\right)^{2}}{x^{2} A_{i}{ }^{2}}+\frac{u(L)^{2}}{L^{2}}}
\end{aligned}
$$

Depending on the value of the thermodynamic constant, $K$, the optimal fraction of $\mathrm{Cu}$-trien consumed to minimize both the instrument uncertainty and the partial exchange systematic error is somewhere between $30 \%$ and $80 \%$ (Figure 6), as suggested empirically for CEC measurements with Co-hex on soils by Orsini and Remy (1976). Since it is not possible to determine $K$ with these simple measurements, we consider most resonable to aim at $30 \%$ consumption (most pessimistic value for $K$ ) because the decrease of $u_{\text {instr }}(C E C)$ beyond $30 \%$ is less important.

\subsection{Quantification of smectite weight fraction in altered volcanic rocks}

A linear correlation is found between the smectite weight fraction and the CEC of altered volcanic rocks, where the only swelling clay mineral is smectite (Figure 7). Due to the complexity of Rietveld refinements in whole rock samples when several types of clays are involved, only samples where a satisfying fit is obtained using only the clay phase "Smectite tri-octahedral with interlayers filled with Ca and 2 water layers" are reported in this figure. In samples where a peak at 7- 


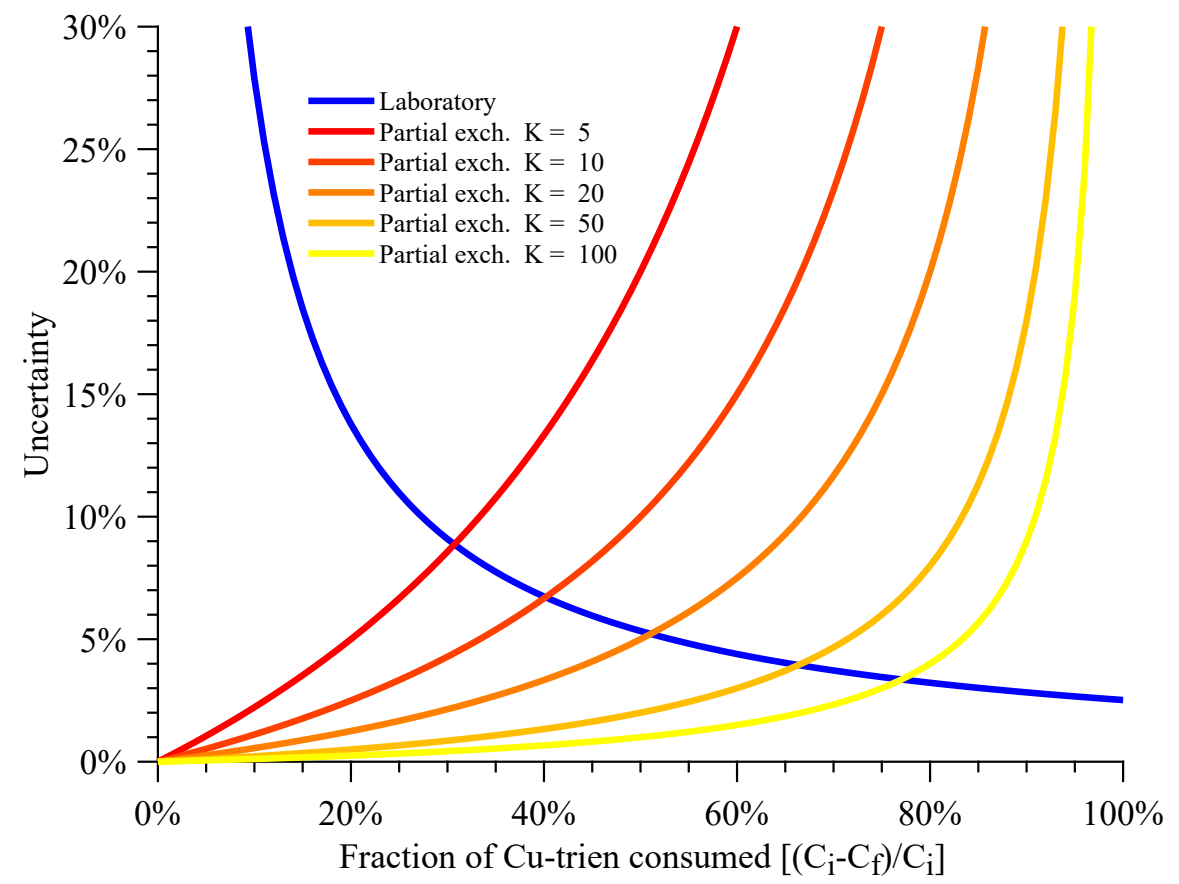

Figure 6: Laboratory uncertainty and "partial exchange" systematic error, as a function of the fraction of Cu-trien consumed.

$7.5 \AA$ is observed (typical of chlorite and chlorite-smectite), the smectite quantity derived from the fit is considered irrelevant for a quantitative comparison with the CEC. An uncertainty on the quantification is calculated by fitting the same diffraction patterns with a different smectite phase: "Saponite with interlayers filled with undetermined cations and 2 water layers". The quantities derived from the fit with the less constrained saponite are systematically lower. The linear fit to the observations shown in Figure 7 has a slope $C E C_{s m e c}=90 \pm$ $5 \mathrm{meq} / 100 \mathrm{~g}$ and a regression coefficient $R^{2}=0.945$. The slope is consistent with the known range of CEC for smectite, $80-120 \mathrm{meq} / 100 \mathrm{~g}$, caused by the permanent negative charge of the crystal lattice, in the range 0.3-0.6 per half unit cell $\mathrm{Si}_{4} \mathrm{O}_{10}(\mathrm{OH})_{2}$, that is compensated for hydrated interlayer cations (e.g. Bouchet et al., 2000). A slope of $C E C_{s m e c, 105^{\circ} \mathrm{C}}=94 \pm 5 \mathrm{meq} / 100 \mathrm{~g}$, with a 
408 regression coefficient of 0.952 , is found when CEC values are corrected for the

409 water loss at $105^{\circ} \mathrm{C}($ Appendix D).

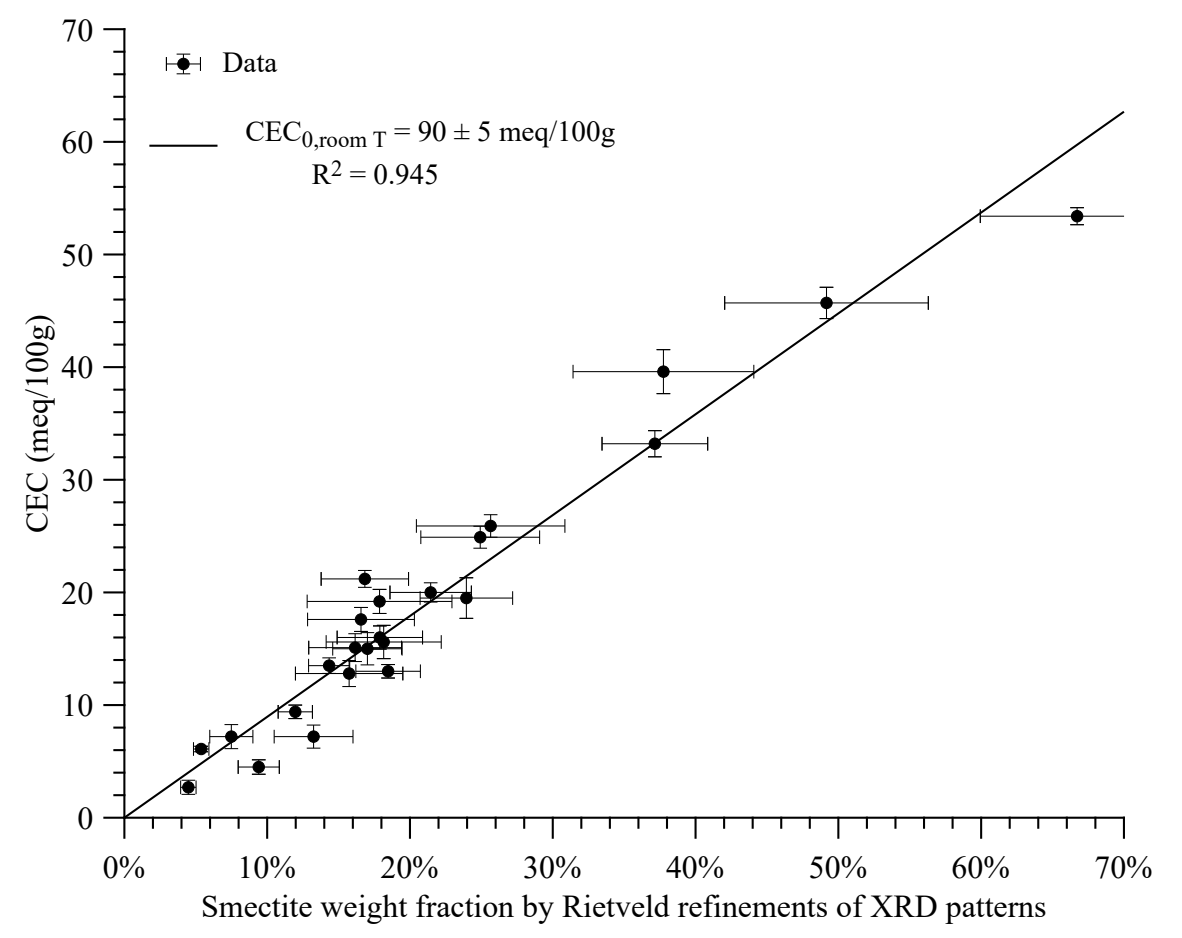

Figure 7: CEC measurements versus smectite quantification by Rietveld refinements of XRD patterns, for samples where smectite is the only swelling clay mineral. The slope and regression coefficient of the fitting line is given in the legend. CEC measurements and XRD scans are carried out on the exact same powders. The same figure, using CEC values corrected for taking the water content into account in each sample, is presented in Appendix D.

410 The contribution of other minerals to the measured CEC is also investigated,

$\mathbf{4 1 1}$ in particular zeolites, illite and chlorite. Zeolites can be divided into two groups:

412 (i) "rigid" zeolites (e.g. laumontite, mesolite, analcime, natrolite and scolecite),

$4 \mathbf{4 1 3}$ whose chemical formula is well-defined and in which extra-framework (other

$4 \mathbf{4 1 4}$ than $\mathrm{Al}$ and $\mathrm{Si}$ ) cations cannot be exchanged and only the water content can

$\mathbf{4 1 5}$ vary and (ii) "flexible" zeolites (e.g. heulandite, chabazite and clinoptilolite),

416 which exhibit a wide and continuous range of extra-framework cation compo-

$4 \mathbf{1 7}$ sitions. Although, CEC of heulandite and clinoptilolite can reach up to 300

$4 \mathbf{1 8} \mathrm{meq} / 100 \mathrm{~g}$ (Fridriksson et al., 2004), CEC measurements by the method de- 
veloped here result in CEC values in the range 0.5-1.5 meq/100g (Lévy et al., 2018). Therefore, the contribution of zeolites to the CEC measured by $\mathrm{Cu}$-trien in altered volcanic samples is negligible.

The CEC of pure illite [Beavers Bend illite - Mankin and Dodd (1961)] is also measured using the same method (back-titration by $\mathrm{Cu}$-trien), yielding $4 \mathrm{meq} / 100 \mathrm{~g}$, which confirms the quasi-absence of non-mica layers in the illite sample (Mankin and Dodd, 1961) and the negligible CEC of pure illite compared to pure smectite (Hower and Mowatt, 1966). Moreover, the CEC of samples containing large amounts of chlorite, as well as in some cases wairakite and other "high-temperature" alteration minerals (epidote, actinolite), but no hint of smectite, is always lower than $0.5 \mathrm{meq} / 100 \mathrm{~g}$, when measured by this method (Lévy et al., 2018). We conclude that the linear trend presented in Figure 7 can be used to estimate the weight fraction of smectite in altered volcanic samples containing wide range of minerals. This weight fraction also includes smectite layers in mixed-layer chlorite-smectite or illite-smectite.

As mentioned in Section 2, the grain size of rock powders used for measurements presented in Figure 7 is strictly below $250 \mu \mathrm{m}$. This is a requirement to transform the CEC measurement into absolute smectite weight fraction. The presence of larger grains (e.g. millimetric size) have less surface exposed during the exchange reaction, which might result in reduced smectite accessibility by the exchange solution and thus smaller measured CEC (Kaufhold et al., 2012). We do observe a discrepancy of $20 \%$ for a high-CEC sample, L99, between the CEC measured with the same initial and optimal conditions but ground to two different sizes. These two measurements were carried out by the Institut National de Recherche en Agronomie in Arras (France), which performs accredited measurements of CEC on soil: (i) using their standard size ( $\leq 2 \mathrm{~mm})$ and (ii) using a smaller size $(\leq 250 \mu \mathrm{m})$ on our request. 
Finally, heterogeneity of core samples from geothermal areas may cause sig${ }_{447}$ nificantly different CEC values depending on which lateral face of the cylindrical ${ }_{448}$ plug is used for the powder. Therefore, crushing and mixing together as much 449 rock sample as possible (e.g. from the two lateral faces) is recommended.

\section{${ }_{450} 4$ Conclusions}

451 In this study, we suggest a modified protocol to minimize the uncertainty of CEC measurements with the $\mathrm{Cu}$-trien method and thus to quantify the smectite content in altered volcanic rocks. We observe that using a fixed mass of sample for rocks covering a wide range of smectite content may cause a relative uncertainty of up to $70 \%$ for samples with low smectite content. We also show that XRD on randomly oriented powders is not sufficient for smectite quantification in samples containing other disordered clay minerals (including smectite-bearing mixed-layers) and/or chlorite. We establish that the fraction of $\mathrm{Cu}$-trien consumed at the end of the reaction needs to be optimized in order to minimize the total uncertainty of the CEC measurement. Instrument uncertainty and systematic "partial exchange" error are anti-correlated with varying fraction of $\mathrm{Cu}$-trien consumed. We suggest that a value of $30 \%$ for this fraction is optimal, as a rule. Finally, we show a linear correlation between the CEC, measured with an adequate $\mathrm{Cu}$-trien consumption, and the smectite weight fraction determined by XRD, for 24 samples containing smectite as the only swelling clay mineral. Our study provides the geothermal industry with a simple method to quantify the smectite weight fraction (pure smectite or expandable layers in mixed-layer clays) of powders from all kinds of altered volcanic rocks. Different spectrophotometric back-titration methods, using for example the Cobalti-hexamine (III) molecule, can be used in the same manner for smectite quantification, since a whole range of thermodynamic constants are considered for the cation exchange 
reaction.

\section{${ }_{473} 5$ Acknowledgments}

${ }_{474}$ L.L. thanks Sigurdur Sveinn Jónsson, Helga Margrét Helgadóttir and Bjarni

${ }_{475}$ Gautason for their help with identifying primary and alteration minerals in 476 XRD patterns, thin sections and microscopic observations. L.L. thanks Heimir

477 Ingimarsson, Christina Guenther and Ester Inga Eyjólfsdóttir for their help 478 with the CEC measurements, as well as Iwona Monika Galezka and Kristinn 479 I. Gudmundsson for ICP measurements and discussion of the results. The au480 thors thank Christophe Nevado, Doriane Delmas and Khaled Oubellouch for 481 high-quality polished thin sections and Jacinthe Caillaud for electron probe 482 data collection and analysis. The authors are also grateful to Landsvirkjun, 483 and especially Ásgrímur Gudmundsson, for providing rock samples used in this work. Finally, the authors thank editor Halldor Armansson, as well as Reiner Dohrmann and another anonymous reviewer for their remarks and suggestions, which very much helped improve the manuscript. 488 grated Methods for Advanced Geothermal Exploration, grant agreement No. 608553) and by a $\mathrm{PhD}$ grant from Paris Sciences et Lettres granted to Léa Lévy.

491

Data availability: the .xrdml files (X-ray diffraction patterns) used for Rietveld quantitative analysis are available as Supplementary Material.

\section{${ }_{493}$ References}

494 Alt, J. C., Honnorez, J., Laverne, C., and Emmermann, R. (1986). "Hydrother495 mal alteration of a $1 \mathrm{~km}$ section through the upper oceanic crust, Deep Sea 
Drilling Project Hole 504B: Mineralogy, chemistry and evolution of seawaterbasalt interactions". In: Journal of Geophysical Research: Solid Earth 91.B10, pp. 10309-10335.

Ammann, L., Bergaya, F., and Lagaly, G. (2005). "Determination of the cation exchange capacity of clays with copper complexes revisited." In: Clay Minerals 40, pp. 441-453.

Ammann, L. (2003). "Cation exchange and adsorption on clays and clay minerals". PhD thesis. Christian-Albrechts Universität Kiel.

Árnason, K., Karlsdóttir, R., Eysteinsson, H., Flóvenz, O. G., and Gudlaugsson, S. T. (2000). "The resistivity structure of high-temperature geothermal systems in Iceland". In: World Geothermal Congress, pp. 923-928.

Beaufort, D., Papapanagiotou, P., Patrier, P., Fujimoto, K., and Kasai, K. (1995). "High-temperature smectites in active geothermal systems". In: Proceedings 8th Water-Rock Interaction Symposium, Vladivostok. Ed. by Y. Kharaka and O. Chudaev. Balkema, Rotterdam., pp. $1071-1076$.

Bergaya F., V. M. (1997). "CEC of clays: Measurement by adsorption of a copper ethylenediamine complex". In: Applied Clay Science 12, pp. 275-280.

Bish, D. L. and Reynolds, R. C. (1989). "Sample preparation for X-ray diffraction". In: Reviews in Mineralogy and Geochemistry 20.1, pp. 73-99.

Bouchet, A., Meunier, A., and Sardini, P. (2000). Minéraux argileux: structure cristalline, identification par diffraction de rayons X. Vol. 23. Editions Elf Exploration.

Bourdelle, F., Parra, T., Beyssac, O., Chopin, C., and Vidal, O. (2013). "Clay minerals as geo-thermometer: A comparative study based on high spatial resolution analyses of illite and chlorite in Gulf Coast sandstones (Texas, U.S.A.)" In: American Mineralogist 98.5-6, pp. 914-926. DOI: 10.2138/am. 2013.4238 
Bril, H., Papapanagiotou, P., Patrier, P., Lenain, J.-F., and Beaufort, D. (1996). "Fluid-rock interaction in the geothermal field of Chipilapa (El Salvador): contribution of fluid-inclusion data". In: European Journal of Mineralogy, pp. $515-532$.

Chester, F. M., Rowe, C., Ujiie, K., Kirkpatrick, J., Regalla, C., Remitti, F., Moore, J. C., Toy, V., Wolfson-Schwehr, M., Bose, S., et al. (2013). "Structure and composition of the plate-boundary slip zone for the 2011 Tohoku-Oki earthquake". In: Science 342.6163, pp. 1208-1211.

Cieselski, H., Sterckeman, T., Santerne, M., and Willery, J. P. (1997). "A comparison between three methods for the determination of cation exchange capacity and exchangeable cations in soils". In: Agronomie, EDP Sciences 17.1, pp. 9-16.

Ciesielski, H., Sterckeman, T., Santerne, M., and Willery, J. P. (1997). "Determination of cation exchange capacity and exchangeable cations in soils by means of cobalt hexamine trichloride. Effects of experimental conditions". In: Agronomie 17.1, pp. 1-7.

Doebelin, N. and Kleeberg, R. (2015). "Profex: a graphical user interface for the Rietveld refinement program BGMN". In: Journal of applied crystallography 48.5, pp. 1573-1580.

Dohrmann, R. (2006a). "Cation exchange capacity methodology II: A modified silver-thiourea method". In: Applied clay science 34.1-4, pp. 38-46.

- (2006b). "Cation exchange capacity methodology III: correct exchangeable calcium determination of calcareous clays using a new silver-thiourea method". In: Applied Clay Science 34.1-4, pp. 47-57.

Dohrmann, R. and Kaufhold, S. (2009). "Three new, quick CEC methods for determining the amounts of exchangeable calcium cations in calcareous clays". In: Clays and Clay Minerals 57.3, pp. 338-352. 
Durrant, C. B., Begg, J. D., Kersting, A. B., and Zavarin, M. (2018). "Cesium sorption reversibility and kinetics on illite, montmorillonite, and kaolinite". In: Science of the Total Environment 610, pp. 511-520.

Flóvenz, O. G., Spangenberg, E., Kulenkampf, J., Árnason, K., Karlsdóttir, R., and Huenges, E. (2005). "The role of electrical interface conduction in geothermal exploration". In: Proceedings of World Geothermal Congress 2005.

Flóvenz, O. G., Hersir, G. P., Sæmundsson, K., Ármannsson, H., and Friðriksson, T. (2012). "7.03 - Geothermal Energy Exploration Techniques". In: Comprehensive Renewable Energy. Ed. by A. Sayigh. Oxford: Elsevier, pp. 51 -95. DOI: https ://doi.org/10.1016/B978-0-08-087872-0.00705-8

Flóvenz, O., Georgsson, L., and Árnason, K. (1985). "Resistivity structure of the upper crust in Iceland". In: Journal of Geophysical Research 90.B12, pp. 10136-10150.

Fridriksson, T., Neuhoff, P. S., Vinani, B. E., and Bird, D. K. (2004). "Experimental determination of thermodynamic properties of ion-exchange in heulandite: binary ion-exchange experiments at 55 and $85^{\circ} \mathrm{C}$ involving $\mathrm{Ca} 2+, \mathrm{Sr} 2+, \mathrm{Na}+$ and $\mathrm{K}+$ ". In: American Journal of Science 304, pp. 287332.

Heap, M., Lavallée, Y., Petrakova, L., Baud, P., Reuschle, T., Varley, N., and Dingwell, D. B. (2014). "Microstructural controls on the physical and mechanical properties of edifice-forming andesites at Volcán de Colima, Mexico". In: Journal of Geophysical Research: Solid Earth 119.4, pp. 2925-2963. Henry, P. (1997). "10. Relationship between porosity, electrical conductivity, and cation exchange capacity in Barbados wedge sediments". In: Proceedings of the Ocean Drilling Program. Scientific Results. Vol. 156, pp. 183-195. 
Hower, J. and Mowatt, T. C. (1966). "The mineralogy of illites and mixed-layer illite/montmorillonites". In: American Mineralogist 51.5-6, pp. 825-854.

Hyndman, R. D., Yamano, M., and Oleskevich, D. A. (1997). "The seismogenic zone of subduction thrust faults". In: Island Arc 6.3, pp. 244-260. DOI: 10. $1111 / \mathrm{j} .1440-1738.1997 . t b 00175 \cdot \mathrm{x}$

Joint Committee for Guides in Metrology (JCGM) (2008). Evaluation of measurement data - Guide to the expression of uncertainty in measurement (GUM). Bureau International des Poids et Mesures.

Kaufhold, S. and Dohrmann, R. (2003). "Beyond the Methylene Blue Method: Determination of the Smectite Content using the Cutriene Method". In: Zeitschrift für Angewandte Geologie 49, pp. 13-17.

Kaufhold, S, Dill, H., and Dohrmann, R (2012). "Clay mineralogy and rock strength of a mid-German diabase: implications for improved quality control". In: Clay Minerals 47.4, pp. 419-428.

Kaufhold, S, Grissemann, C, Dohrmann, R, Klinkenberg, M, and Decher, A (2014). "Comparison of three small-scale devices for the investigation of the electrical conductivity/resistivity of swelling and other clays". In: Clays and clay minerals 62.1 , pp. 1-12.

Kaufhold, S., Dohrmann, R., Klinkenberg, M., and Noell, U. (2015). "Electrical conductivity of bentonites". In: Applied clay science 114, pp. 375-385.

Kristmannsdottir, H. (1979). "Alteration of basaltic rocks by hydrothermal activity at 100-300C". In: Developments in sedimentology 27, pp. 359-367.

Kristmannsdóttir, H. and Tómasson, J. (1978). Zeolite zones in geothermal areas in Iceland. Report OS JHD 7649. Orkustofnun, Jarðhita deild.

$\mathrm{Ku}, \mathrm{H}$. H. et al. (1966). "Notes on the use of propagation of error formulas". In: Journal of Research of the National Bureau of Standards 70.4. 
Lagaly, G. (1981). "Characterization of clays by organic compounds". In: Clay Minerals 16.1, pp. 1-21.

Lévy, L., Gibert, B., Sigmundsson, F., Flóvenz, O. G., Hersir, G. P., Briole, P., and Pezard, P. A. (2018). "The role of smectites in the electrical conductivity of active hydrothermal systems: electrical properties of core samples from Krafla volcano, Iceland". In: Geophysical Journal International 215.3, pp. $1558-1582$.

Mankin, C. J. and Dodd, C. G. (1961). "Proposed reference illite from the Ouachita Mountains of southeastern Oklahoma". In: Clays and Clay Minerals 10.1 , pp. $372-379$.

Maraqah, H., Li, J., and Whittingham, M. S. (1990). "Ion transport in single crystals of the clay-like aluminosilicate, vermiculite". In: MRS Online Proceedings Library Archive 210. DOI: https://doi.org/10.1557/PROC-210351, p. 351.

Meier, L. and Kahr, G. (1999). "Determination of the Cation Exchange Capacity (CEC) of Clay Minerals Using the Complexes of Copper(II) Ion with Triethylenetetramine and Tetraethylenepentamine". In: Clays and Clay Minerals 47.3 , pp. $386-388$.

Meller, C. (2014). "Localization and Characterization of Hydrothermal Alteration Zones in a Geothermal Reservoir and Their Significance for Rock Mechanics". PhD thesis. KIT-Bibliothek.

Orsini, L and Remy, J. (1976). "Utilisation du chlorure de cobaltihexamine pour la détermination simultanée de la capacité d'échange et des bases échangeables des sols". In: Sci. Sol 4, pp. 269-275.

Patrier, P., Papapanagiotou, P., Beaufort, D., Traineau, H., Bril, H., and Rojas, J. (1996). "Role of permeability versus temperature in the distribution of the fine $(\leq 0.2 \mu \mathrm{m})$ clay fraction in the Chipilapa geothermal system 
(El Salvador, Central America)". In: Journal of Volcanology and Geothermal Research 72.1, pp. 101-120. DOI: https://doi.org/10.1016/03770273(95) 00078-X

Pezard, P. A. (1990). "Electrical properties of mid-ocean ridge basalt and implications for the structure of the upper oceanic crust in Hole 504B". In: Journal of Geophysical Research 95.B6, p. 9237. DOI: 10.1029/JB095iB06p09237.

Raven, M. D. and Self, P. G. (2017). "Outcomes of 12 years of the Reynolds Cup quantitative mineral analysis round robin". In: Clays and Clay Minerals 65.2, pp. $122-134$.

Reinoso-Maset, E., Hainos, D., and Ly, J. (2012). "Sorption of uranium (VI) and radium (II) at trace level onto kaolinite and montmorillonite". In: VM Goldschmidt Conference.

Revil, A. and Glover, P. W. J. (1997). "Theory of ionic-surface electrical conduction in porous media". In: Physical Review B 55.3, pp. 1757-1773.

Revil, A., Cathles, L. M., Losh, S., and Nunn, J. A. (1998). "Electrical conductivity in shaly sands with geophysical applications". In: Journal of Geophysical Research: Solid Earth 103.B10, pp. 23925-23936.

Rink, M. and Schopper, J. R. (1974). "Interface conductivity and its implications to electric logging". In: Society of Petrophysicists and Well-Log Analysts. Society of Petrophysicists and Well-Log Analysts.

Robin, V., Tertre, E., Beaufort, D., Regnault, O., Sardini, P., and Descostes, M. (2015). "Ion exchange reactions of major inorganic cations $(\mathrm{H}+, \mathrm{Na}+, \mathrm{Ca} 2+$, $\mathrm{Mg} 2+$ and $\mathrm{K}+$ ) on beidellite: Experimental results and new thermodynamic database. Toward a better prediction of contaminant mobility in natural environments". In: Applied Geochemistry 59, pp. 74-84.

Robin, V., Tertre, E., Beaucaire, C., Regnault, O., and Descostes, M. (2017). "Experimental data and assessment of predictive modeling for radium ion- 
exchange on beidellite, a swelling clay mineral with a tetrahedral charge". In: Applied Geochemistry 85, pp. 1-9.

Stanjek, H. and Künkel, D. (2016). "CEC determination with Cutriethylenetetramine: recommendations for improving reproducibility and accuracy". In: Clay Minerals 51.1, pp. 1-17.

Taut, T., Kleeberg, R., and Bergmann, J. (1998). "Seifert Software: The new Seifert Rietveld program BGMN and its application to quantitative phase analysis". In: Materials Structure 5.1, pp. 57-66.

Tertre, E. (2014). "Modélisation des propriétés d'adsorption des minéraux argileux gonflants vis-à-vis de cations inorganiques. Interfaces continentales, environnement." Habilitation à diriger des recherches. Université de Poitiers.

Vogt, K. and Köster, H. M. (1978). "Zur Mineralogie, Kristallchemie und Geochemie einiger Montmorillonite aus Bentoniten". In: Clay Minerals 13.1, pp. 25-43.

Von Reichenbach, H. G. (1968). "Cation exchange in the interlayers of expansible layer silicates". In: Clay Minerals 7.3, pp. 331-341.

Waxman, M. H. and Smits, L. J. M. (1968). "Electrical conductivities in oilbearing shaly sands". In: Soc. Pet. Eng. J. 8, pp. 107-122.

\section{A Effect of preferred orientation on X-ray diffrac- tion patterns: the case of heulandite}

The effect on XRD patterns of preferred orientation when samples are backloaded onto sample holders, is illustrated in Figure A.1. The relative intensity of the heulandite peak at low angle (about $10^{\circ} 2 \theta$ ), compared to the other peaks, is much higher when sample is back-loaded. The residuals at the end of refinement (gray signal under each pattern) are also higher in this case. 


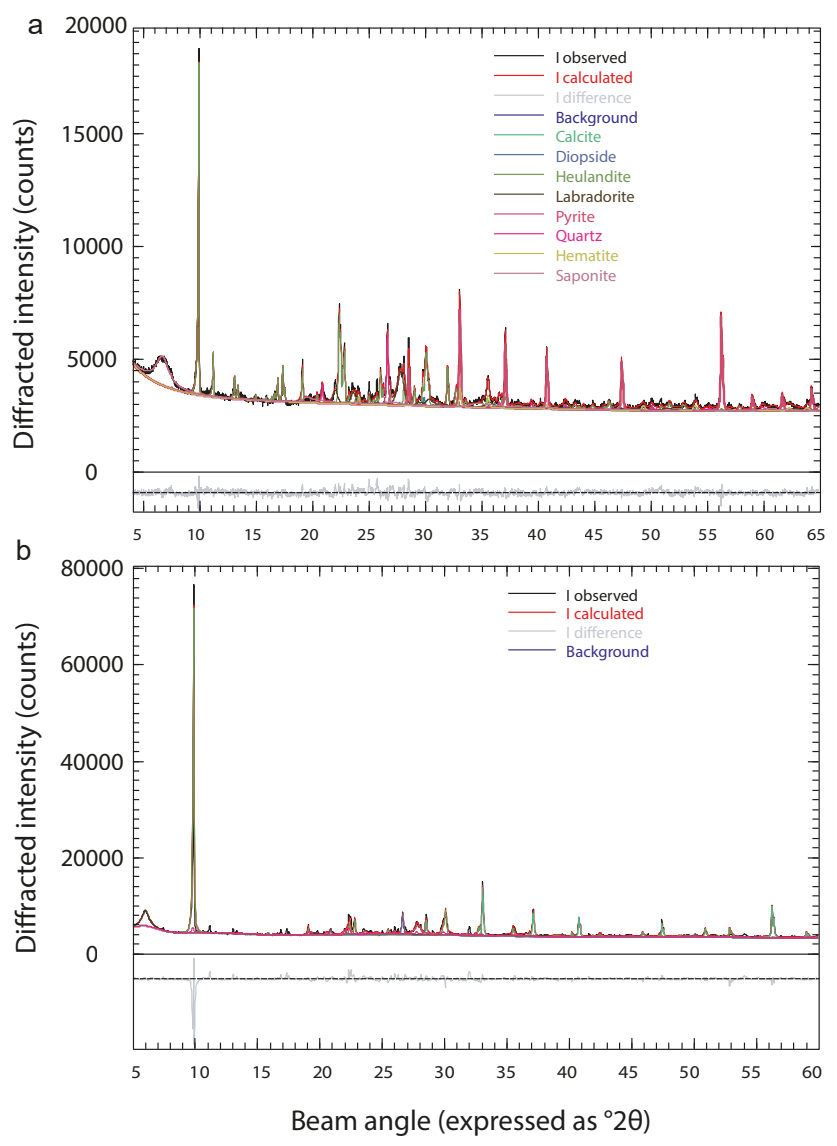

Figure A.1: Effect of preferred orientation on X-ray diffraction pattern for a sample (L02) containing a large amount of heulandite (zeolite). The upper pannel shows the diffraction pattern when the powder is carefully grained and front-loaded. The lower pannel shows the diffraction pattern for the exact same powder but back-loaded. The diffraction peak of heulandite at angle $10^{\circ} 2 \theta$ is four times higher in the lower panel and cannot be correctly fitted.

\section{${ }_{681}$ B Structure files for smectite and chlorite in BGMN

\section{B.1 Chlorite with $\mathrm{Fe} / \mathrm{Mg}$ ratios constrained}

684

PHASE-CHLORITE_Lea //

685 SpacegroupNo=12 HermannMauguin=C12/m1 //

${ }_{686} \quad \mathrm{PARAM}=\mathrm{pa}=0.6 \_0.5^{\wedge} 0.8$ 


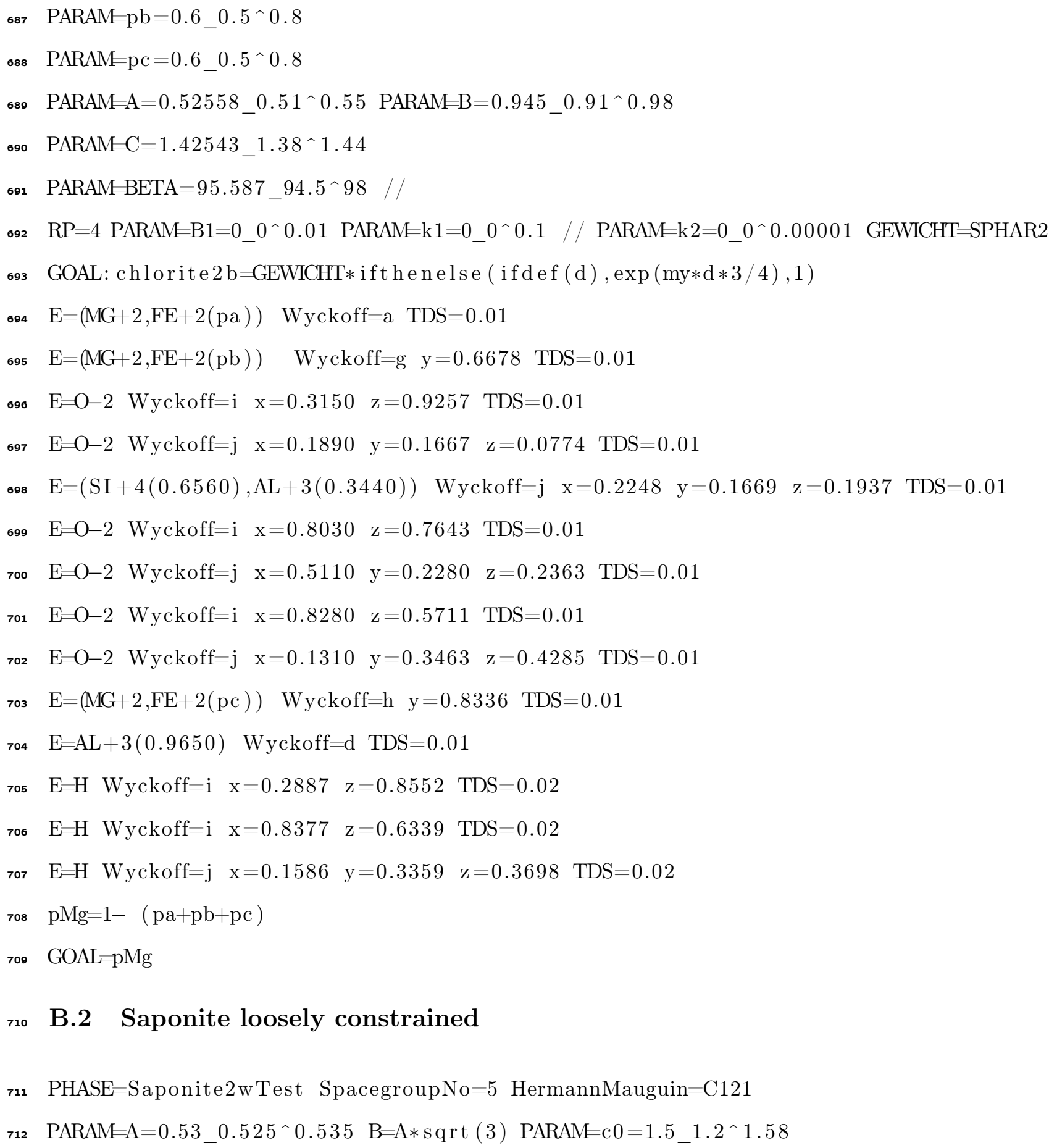

\section{B.2 Saponite loosely constrained}

PHASE $=$ Saponite $2 \mathrm{w}$ Test SpacegroupNo=5 HermannMauguin=C121

$\mathrm{PARAM}=\mathrm{A}=0.53 \_0.525^{\wedge} 0.535 \mathrm{~B}=\mathrm{A} * \operatorname{sqrt}(3) \mathrm{PARAM}=\mathrm{c} 0=1.5 \_1.2^{\wedge} 1.58$ 


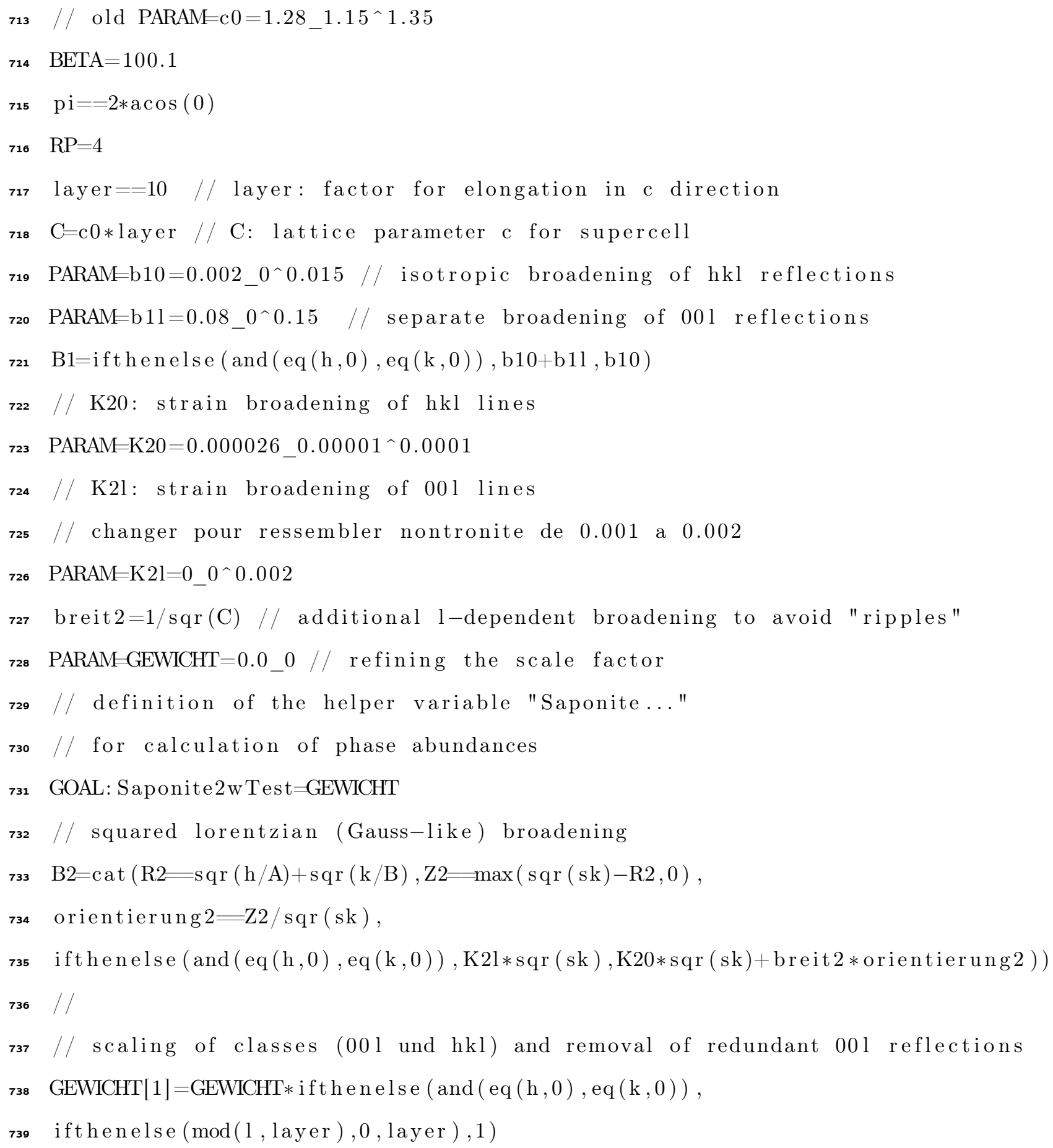




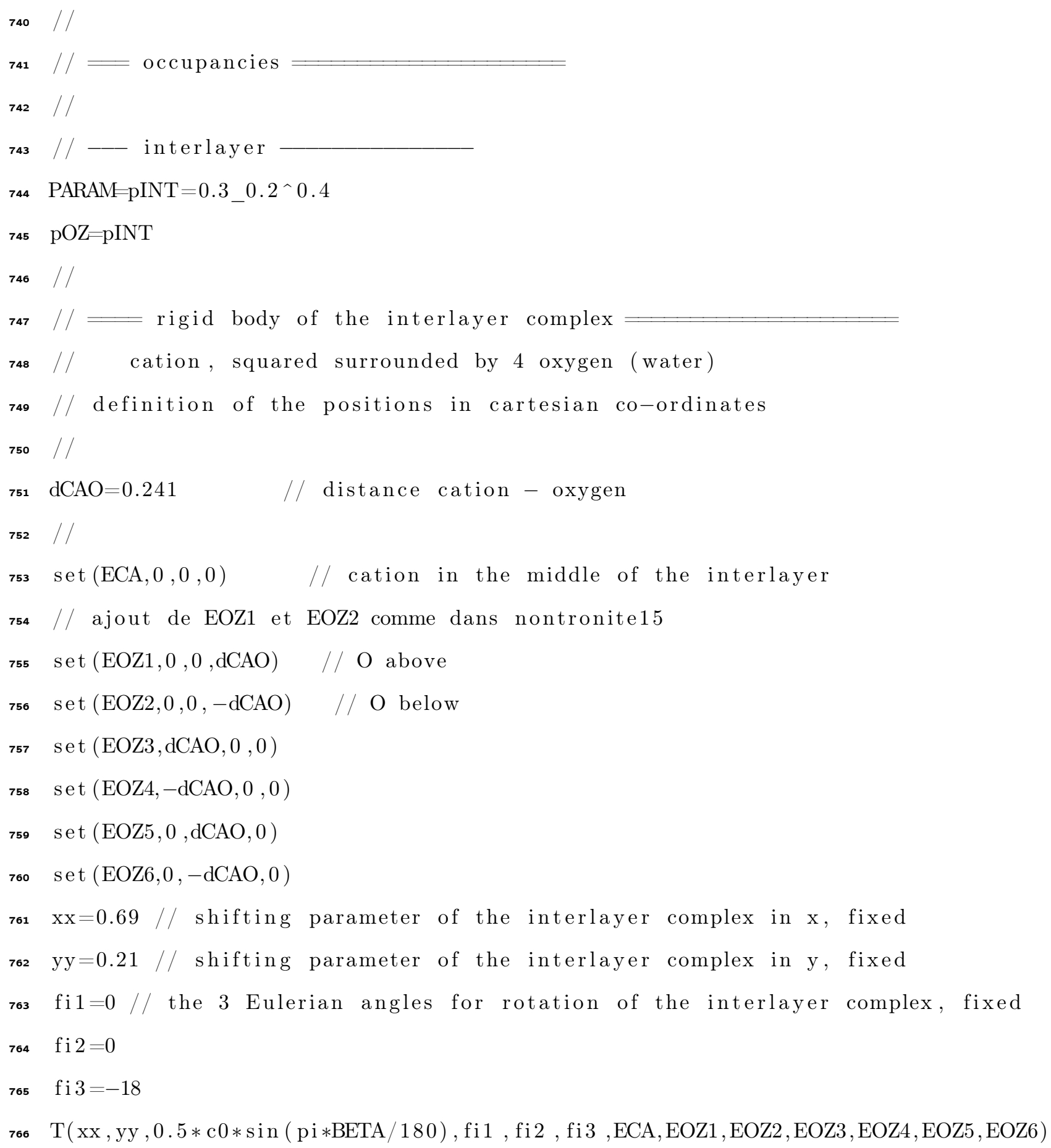




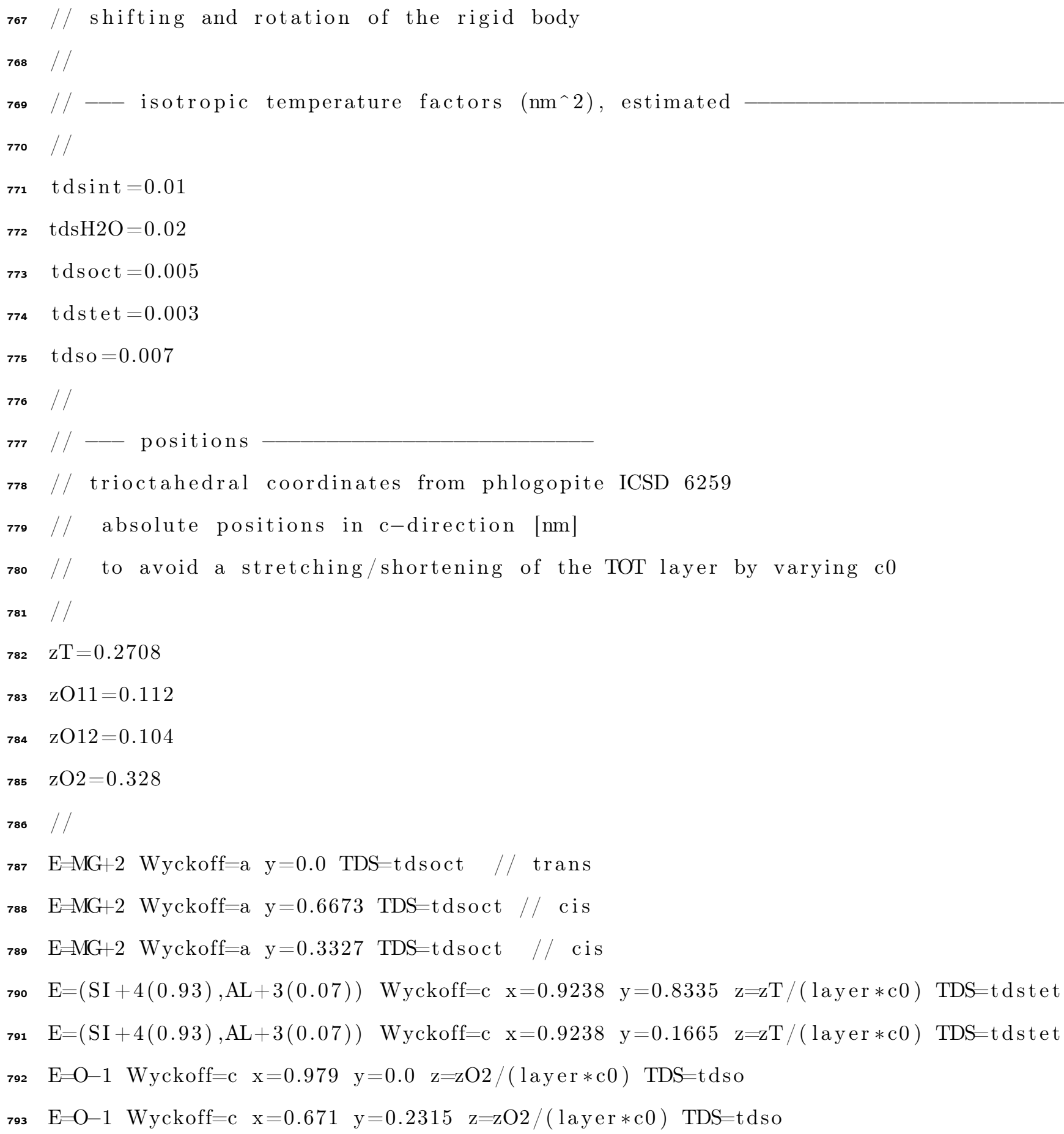


$\mathrm{E}=\mathrm{O}-1$ Wyckoff $=\mathrm{c} \quad \mathrm{x}=0.871 \quad \mathrm{y}=0.1668 \mathrm{z}=\mathrm{zO} 11 /($ layer $* \mathrm{c} 0) \quad$ TDS $=\mathrm{tdso}$

$\mathrm{E}=\mathrm{O}-1$ Wyckoff $=\mathrm{c} \quad \mathrm{x}=0.871 \quad \mathrm{y}=0.8332 \quad \mathrm{z}=\mathrm{zO} 11 /($ layer $* \mathrm{c} 0) \quad$ TDS $=$ tdso

$\mathrm{E}-\mathrm{O}-1 \quad \mathrm{Wyckoff}=\mathrm{c} \quad \mathrm{x}=0.363 \quad \mathrm{y}=0.0 \quad \mathrm{z}=\mathrm{zO} 12 /($ layer $* \mathrm{c} 0) \quad \mathrm{TDS}=\mathrm{tdso}$

$\mathrm{E}=\mathrm{O}-1$ Wyckoff $=\mathrm{c} \quad \mathrm{x}=0.6710 \quad \mathrm{y}=0.7685 \quad \mathrm{z}=\mathrm{zO} 2 /($ layer $* \mathrm{c} 0) \quad \mathrm{TDS}=\mathrm{tdso}$

$/ /$ list of interlayer positions

$/ /$ change NA to CA et $1(\mathrm{pINT})$ to $2(\mathrm{pINT})$ + ajout de 2 ligne EOZ1 et EOZ2

$\mathrm{E}=\mathrm{CA}+2(\mathrm{pINT}) \quad$ Wyckoff $=\mathrm{c} \quad \mathrm{x}=\mathrm{X}(\mathrm{ECA}) \quad \mathrm{y}=\mathrm{Y}(\mathrm{ECA}) \quad \mathrm{z}=\mathrm{Z}(\mathrm{ECA}) \quad$ TDS $=\mathrm{t} \cos \mathrm{t}$

$\mathrm{E}-\mathrm{O}-2(\mathrm{pOZ}) \quad$ Wyckoff $=\mathrm{c} \quad \mathrm{x}=\mathrm{X}(\mathrm{EOZ1}) \quad \mathrm{y}=\mathrm{Y}(\mathrm{EOZ1}) \quad \mathrm{z}=\mathrm{Z}(\mathrm{EOZ1}) \quad$ TDS-tdsH2O

$\mathrm{E}=\mathrm{O}-2(\mathrm{pOZ}) \quad$ Wyckoff $=\mathrm{c} \quad \mathrm{x}=\mathrm{X}(\mathrm{EOZ2}) \quad \mathrm{y}=\mathrm{Y}(\mathrm{EOZ2}) \quad \mathrm{z}=\mathrm{Z}(\mathrm{EOZ2}) \quad$ TDS=tdsH2O

$\mathrm{E}=\mathrm{O}-2(\mathrm{pOZ}) \quad$ Wyckoff $=\mathrm{c} \quad \mathrm{x}=\mathrm{X}(\mathrm{EOZ3}) \quad \mathrm{y}=\mathrm{Y}(\mathrm{EOZ3}) \quad \mathrm{z}=\mathrm{Z}(\mathrm{EOZ3}) \quad$ TDS $=\mathrm{tdsH} 2 \mathrm{O}$

$\mathrm{E}-\mathrm{O}-2(\mathrm{pOZ}) \quad$ Wyckoff $=\mathrm{c} \quad \mathrm{x}=\mathrm{X}(\mathrm{EOZ} 4) \quad \mathrm{y}=\mathrm{Y}(\mathrm{EOZ} 4) \quad \mathrm{z}=\mathrm{Z}(\mathrm{EOZ} 4) \quad \mathrm{TDS}=\mathrm{tdsH} 2 \mathrm{O}$

$\mathrm{E}=\mathrm{O}-2(\mathrm{pOZ}) \quad$ Wyckoff $=\mathrm{c} \quad \mathrm{x}=\mathrm{X}(\mathrm{EOZ}) \quad \mathrm{y}=\mathrm{Y}(\mathrm{EOZ}) \quad \mathrm{z}=\mathrm{Z}(\mathrm{EOZ} 5) \quad$ TDS=tdsH2O

$\mathrm{E}-\mathrm{O}-2(\mathrm{pOZ}) \quad$ Wyckoff $=\mathrm{c} \quad \mathrm{x}=\mathrm{X}(\mathrm{EOZ6}) \quad \mathrm{y}=\mathrm{Y}(\mathrm{EOZ} 6) \quad \mathrm{z}=\mathrm{Z}(\mathrm{EOZ6}) \quad$ TDS $=\mathrm{tdsH} 2 \mathrm{O}$

\section{B.3 Tri-octahedral smectite, interlayer spaces filled with}

\section{$\mathrm{Ca}$ and two water layers}

\section{PHASE$=$ Smectitetri_2w_Ca}

SpacegroupNo $=5$ HermannMauguin $=\mathrm{C} 121$

PARAM $=\mathrm{B}=0.93 \_0.900^{\wedge} 0.930 \mathrm{~A}=\mathrm{B} / \mathrm{sqrt}(3)-0.0015 \mathrm{PARAM}=\mathrm{c} 0=1.50 \_1.42^{\wedge} 1.6$

$\mathrm{BETA}=100.2$

$\mathrm{pi}==2 * \operatorname{acos}(0)$

$\mathrm{RP}=4$

layer $==10$ // layer: factor for elongation in c direction

$\mathrm{C}=\mathrm{c} 0 *$ layer $/ / \mathrm{C}$ : lattice parameter $\mathrm{c}$ for supercell

PARAM $=\mathrm{b} 10=0.002 \_0 \wedge 0.015 / /$ isotropic broadening of hkl reflections PARAM $=b 1 \mathrm{l}=0.03 \_0 \wedge 0.1 \quad / /$ separate broadening of 001 reflections 


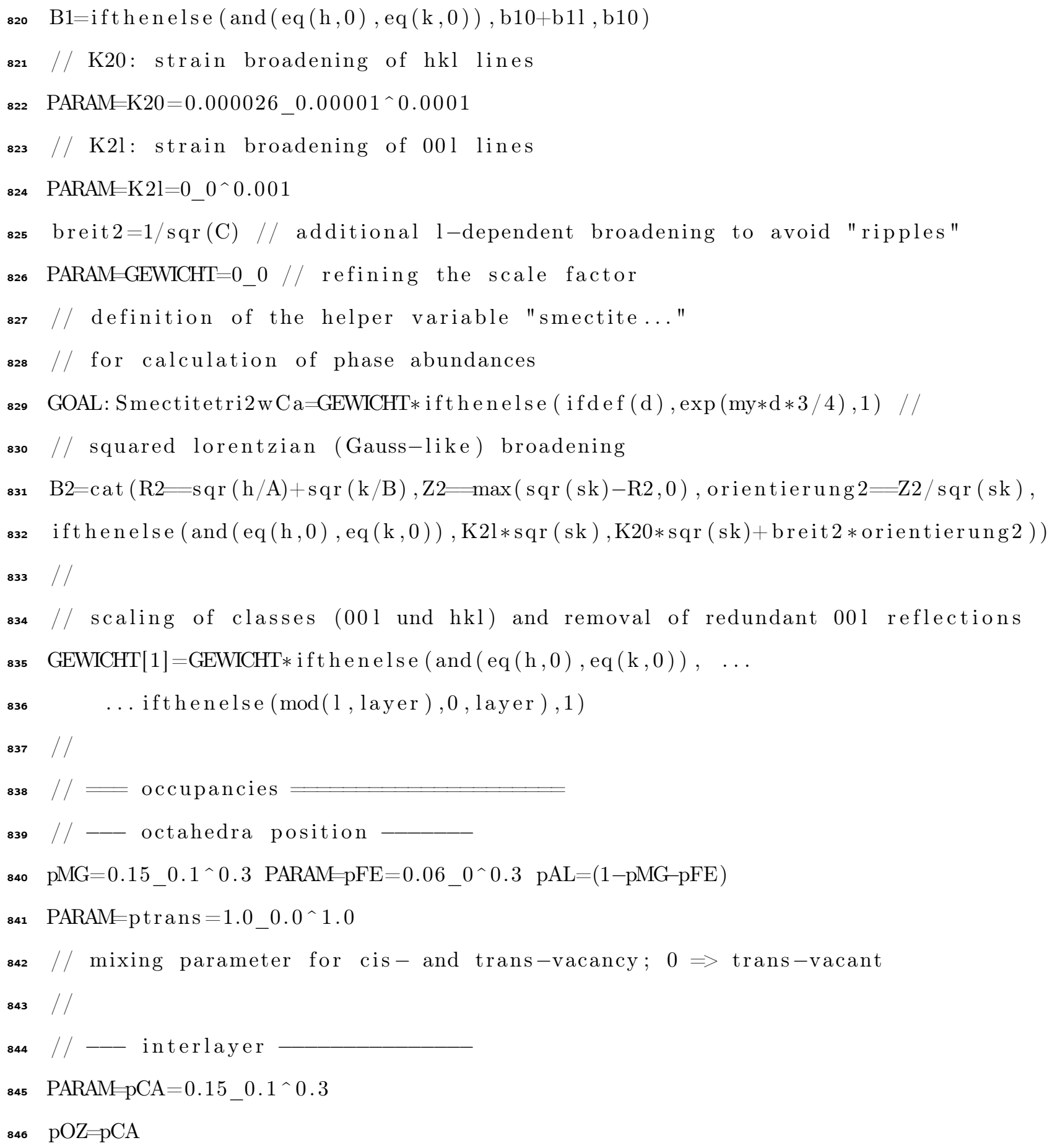




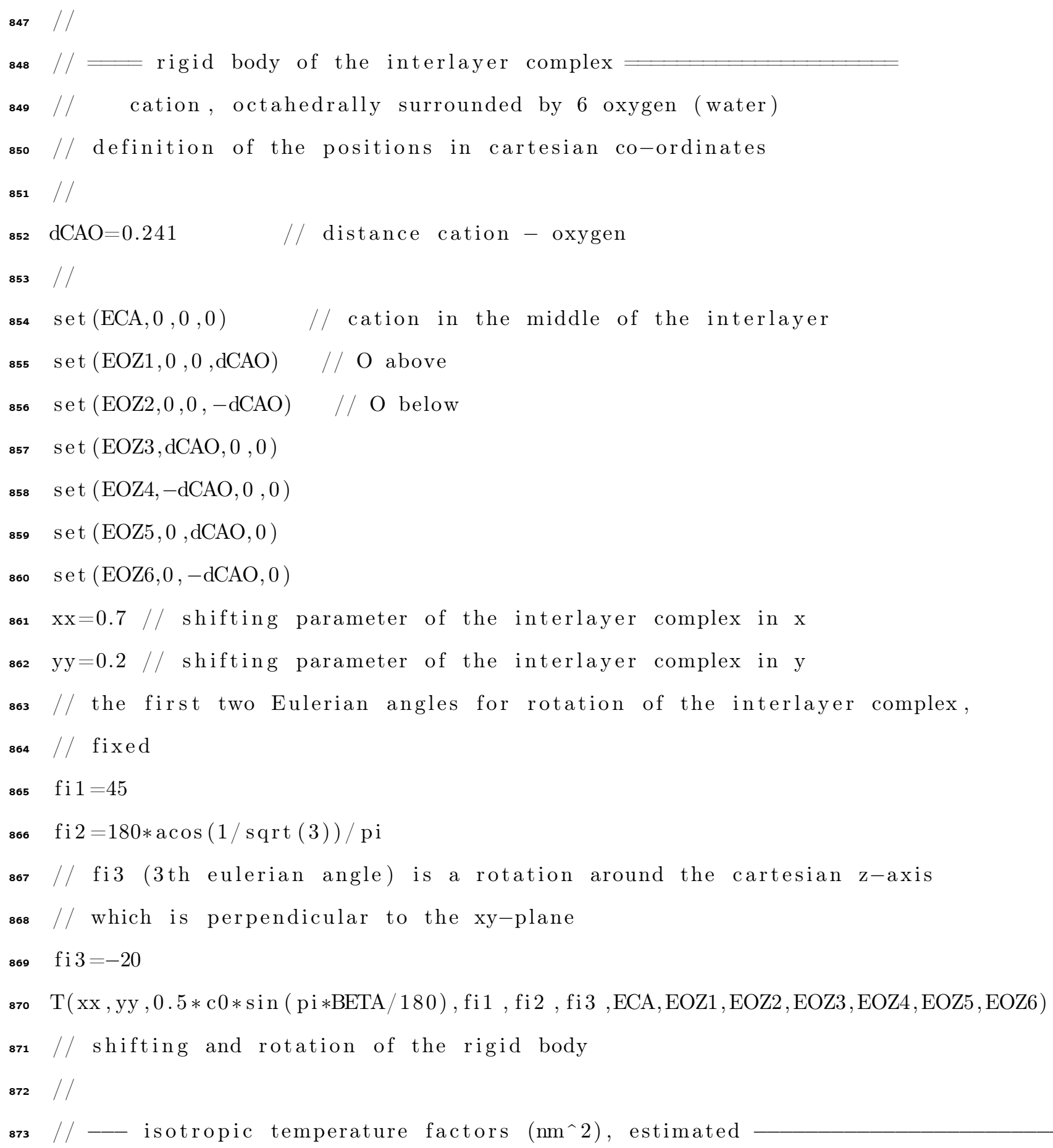




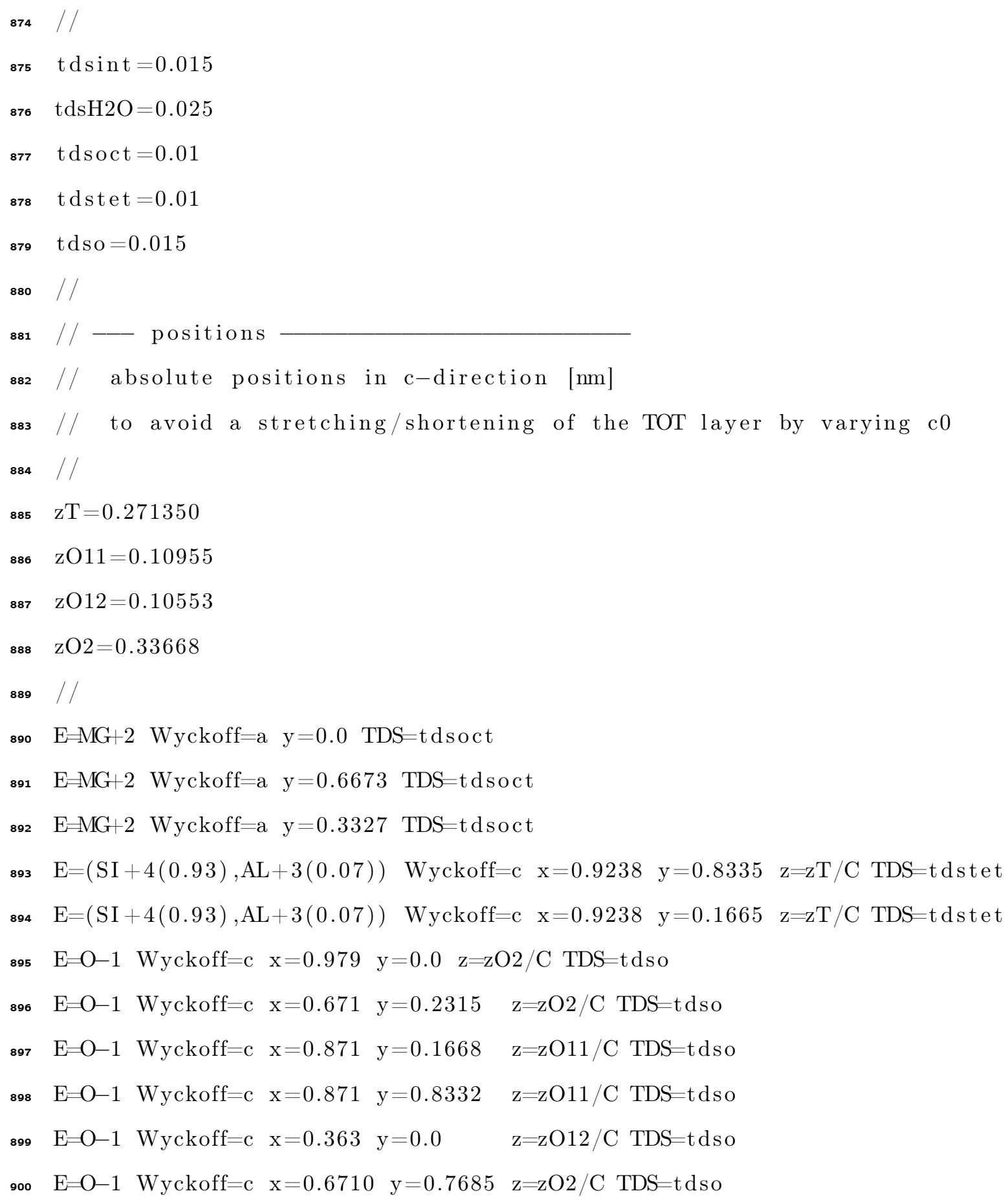




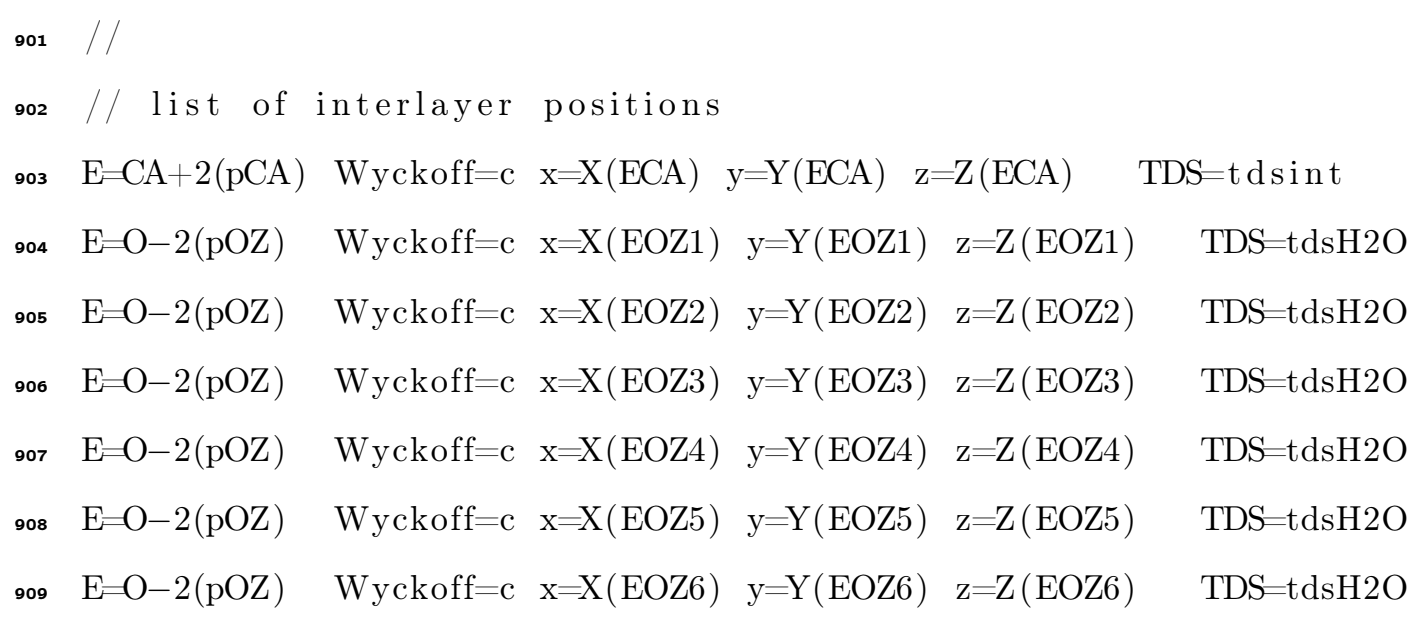




\section{More details about the CEC protocol and the sources of uncertainty}

\section{C.1 Preparation of Cu-trien solutions and calibration of the spectrophotometer}

Exchange solutions are prepared by mixing copper sulphate $\mathrm{CuSO}_{4}$ and the organic compound tri-ethylene-tetramine "trien", in stoechiometric proportions, in a $1 \mathrm{~L}$ volumetric flask. The theoretical concentration of the stock solution is calculated following Equation 18 .

$$
C_{\text {stock }}=\frac{\min \left(\frac{m_{\mathrm{CuSO}_{4}}}{M_{\mathrm{CuSO}_{4}}} ; \frac{m_{\text {trien }}}{M_{\text {trien }}}\right)}{V_{\text {tot }}}
$$

where $m_{\mathrm{CuSO}_{4}}$ and $m_{\text {trien }}$ are the masses of $\mathrm{CuSO}_{4}$ and "trien", in g, $\mathrm{M}_{\mathrm{CuSO}_{4}}$ and $M_{\text {trien }}$ are the molar masses of $\mathrm{CuSO}_{4}$ and "trien", in $\mathrm{g} / \mathrm{mol}$ and $V_{\text {tot }}$ is the total volume of the solution, in L. The masses of $\mathrm{CuSO}_{4}$ and "trien" are calculated to obtain a final concentration of $0.01 \mathrm{M} \mathrm{Cu}$-trien (e.g. $m_{\mathrm{CuSO}_{4}}=$ $1.6114 \mathrm{~g}$ (anhydrous) and $m_{\text {trien }}=1.4941 \mathrm{~g}$ ).

The complex "Cu-trien" is formed by stoichiometric reaction between the two compounds, so that the quantity of $\mathrm{Cu}$-trien formed (in mol) corresponds to the quantity of the compound initially present in lesser quantity, the "limiting reactant". According to Stanjek and Künkel (2016), one has to avoid using an excess of "trien" in the preparation, due to a possible complexation of trien with the interlayer cations of smectite (e.g. $\mathrm{Ca}, \mathrm{Mg}$ ) that would prevent a later exchange with Cu-trien. Since the "trien" compound (from Sigma-Aldrich) has a purity of $\geq 97 \%$ (see also in Ammann, 2003; Stanjek and Künkel, 2016), and the masses are calculated as if trien were $100 \%$ pure, $\mathrm{CuSO}_{4}$ is theoretically in excess in our preparation. 
Table C.1: Comparison of theoretical (conc. theo.) and ICP-measured $\mathrm{Cu}$ concentration (conc. ICP) in six Cu-trien solutions and two $\mathrm{CuSO} 4 \mathrm{solutions.}$ The first six rows correspond to $\mathrm{Cu}$-trien solutions whose ICP-measured $\mathrm{Cu}$ concentration are used for the calibration curve in Figure C.1 The two last rows correspond to $\mathrm{CuSO}_{4}$ solutions, prepared with pentahydrated and anhydrous solids.

\begin{tabular}{llll} 
Solution & $\begin{array}{l}\text { Conc. ICP } \\
\text { mol/L }\end{array}$ & $\begin{array}{l}\text { Conc. theo } \\
\text { mol/L }\end{array}$ & Err \\
\hline Cu-trien StdA & $3.45 \mathrm{E}-04$ & $3.59 \mathrm{E}-04$ & $4 \%$ \\
Cu-trien StdB & $1.04 \mathrm{E}-03$ & $9.99 \mathrm{E}-04$ & $-4 \%$ \\
Cu-trien StdD & $1.63 \mathrm{E}-03$ & $1.68 \mathrm{E}-03$ & $3 \%$ \\
Cu-trien StdE & $2.63 \mathrm{E}-03$ & $2.53 \mathrm{E}-03$ & $-4 \%$ \\
$\mathrm{Cu}-$-trien 1:6 a & $1.58 \mathrm{E}-03$ & $1.52 \mathrm{E}-03$ & $3 \%$ \\
Cu-trien 1:6 b & $1.50 \mathrm{E}-03$ & $1.52 \mathrm{E}-03$ & $-2 \%$ \\
CuSO4 (pentahyd.) & $1.01 \mathrm{E}-02$ & $1.00 \mathrm{E}-02$ & $1 \%$ \\
CuSO4 (anhyd.) & $9.73 \mathrm{E}-03$ & $1.00 \mathrm{E}-02$ & $-3 \%$
\end{tabular}

Most of the exchange solutions are prepared with anhydrous $\mathrm{CuSO}_{4}$. Since anhydrous $\mathrm{CuSO}_{4}$ is an hygroscopic compound and might have slightly rehydrated during storage, we measure the $\mathrm{Cu}$ concentration of both $\mathrm{Cu}$-trien and $\mathrm{CuSO}_{4}$ solutions by ICP (calibrated with a standard for Copper at the wavelength $324.754 \mathrm{~nm}$ ). We compare the measured concentrations to the theoretical solutions, calculated as if it were perfectly anhydrous (Table C.1). ICP results indicate that the theoretical $\mathrm{Cu}$ concentrations in the $\mathrm{CuSO}_{4}$ solutions, prepared with anhydrous and pentahydrated solid $\mathrm{CuSO}_{4}$, are overestimated by $2.7 \%$ and underestimated by $0.8 \%$, respectively. The relative difference in $\mathrm{Cu}$ concentration of $6 \mathrm{Cu}$-trien solutions, all prepared with anhydrous $\mathrm{CuSO}_{4}$, caries between $-4 \%$ and $4 \%$ (Table C.1). This indicates that no systematic error in the $\mathrm{Cu}$ concentration (due to possible rehydration and thus increase of the molar mass) shall be taken into account in the calculations.

Four independent $\mathrm{Cu}$-trien stock solutions and respective dilutions are used for calibrating the spectrophotometer. This set of solutions includes the $\mathrm{Cu}$ trien solutions whose $\mathrm{Cu}$ concentration is measured by ICP (Table C.1). It also includes two $\mathrm{Cu}$-trien solutions directly prepared with the two $\mathrm{CuSO}_{4}$ solutions measured by ICP beforehand. In these cases, the mass of solution is weighted and a mass of "trien" corresponding to a stoechiometric ratio between $\mathrm{Cu}$ and 
952

953

954

955

trien is mixed with deionized water and added to the copper sulphate solution in a $1 \mathrm{~L}$ volumetric flask.

The corresponding calibration curve, presented in Figure C.1, shows that the multiplicative factor $L$ between absorbance and $\mathrm{Cu}$-trien concentration $(A=$ $L[C u-$ trien $])$ is determined with satisfying accuracy $(L=145.4 \pm 0.9 \mathrm{~L} / \mathrm{mol})$.

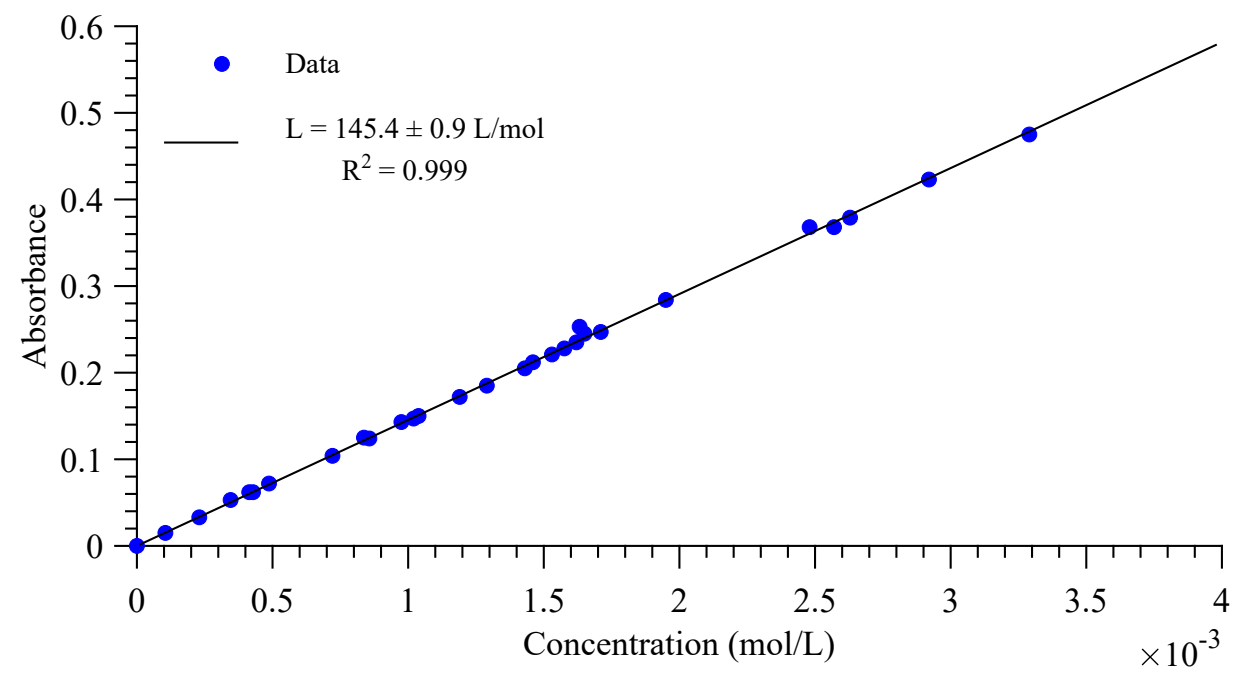

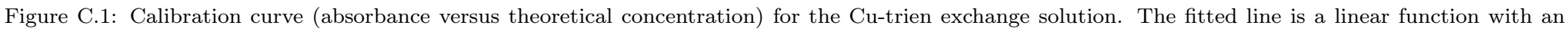

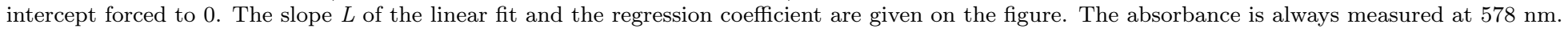

\section{${ }_{957}$ C.2 Contact time with Cu-trien}

${ }_{958}$ A test is carried out on sample L126 to evaluate whether longer contact times

959 with $\mathrm{Cu}$-trien might lead to increased exchange. The CEC measured after 5

960 and 60 minutes are $53.4 \pm 0.7 \mathrm{meq} / 100 \mathrm{~g}$ and $53.1 \pm 0.7 \mathrm{meq} / 100 \mathrm{~g}$, respectively.

${ }_{961}$ We consider the difference between these two numbers not signficant, which confirms that 5 minutes is a sufficient time for this type of samples. 


\section{${ }_{9 ø 3}$ D Water content and CEC correction}

964 CEC measurements are carried out on rock samples dried at room temperature. The CEC values presented in this study do not include a correction for

966 the water content in the samples. In particular, the slope presented in Figure 967 corresponds to the average CEC of smectite in samples dried at room tem968 perature, i.e. containing up to $7 \%$ of bound water molecules. We present in 969 Table D.1 measurements of the water content and corrected CEC values for all 970 samples presented in this study. The water loss is quantified by drying a given 971 mass of each sample at $105^{\circ} \mathrm{C}$. Figure D.1 shows the correlation between CEC, $\mathbf{9 7 2}$ as corrected for the water content, and smectite content. This slope results in 973 a CEC of pure smectite slightly higher than when considering the uncorrected 974 CEC values. 
Table D.1: Water loss at $105^{\circ} \mathrm{C}$ and correction of the CEC values to take into account the water content.

\begin{tabular}{|c|c|c|c|}
\hline ID & $\begin{array}{l}\text { Water content } \\
\text { wt.\% }\end{array}$ & $\begin{array}{l}\text { CEC (no correction) } \\
\mathrm{meq} / 100 \mathrm{~g}(\text { room } \mathrm{T})\end{array}$ & $\begin{array}{l}\text { CEC corrected } \\
\text { meq/100g }\left(105^{\circ} \mathrm{C}\right)\end{array}$ \\
\hline $\begin{array}{l}\text { L02 } \\
\end{array}$ & $3.1 \%$ & 13.5 & 14.0 \\
\hline L04 & $2.4 \%$ & 17.6 & 18.0 \\
\hline L05 & $1.0 \%$ & 6.1 & 6.2 \\
\hline L06 & $2.6 \%$ & 7.2 & 7.4 \\
\hline L09 & $6.0 \%$ & 25.9 & 27.6 \\
\hline L10 & $3.9 \%$ & 15.6 & 16.3 \\
\hline L11 & $2.1 \%$ & 24.9 & 25.5 \\
\hline L12 & $1.3 \%$ & 2.7 & 2.7 \\
\hline L14 & $3.6 \%$ & 33.2 & 34.4 \\
\hline L15 & $1.8 \%$ & 15.0 & 15.3 \\
\hline L16 & $1.6 \%$ & 4.5 & 4.6 \\
\hline L19 & $2.0 \%$ & 15.1 & 15.4 \\
\hline L21 & $2.9 \%$ & 19.2 & 19.8 \\
\hline L22 & $2.4 \%$ & 21.2 & 21.7 \\
\hline L26 & $0.9 \%$ & 12.8 & 12.9 \\
\hline L28 & $2.7 \%$ & 13.0 & 13.4 \\
\hline L29 & $1.5 \%$ & 9.4 & 9.6 \\
\hline L30 & $1.3 \%$ & 7.2 & 7.3 \\
\hline L31 & $2.4 \%$ & 20.0 & 20.5 \\
\hline L119 & $7.2 \%$ & 45.7 & 49.2 \\
\hline L40 & $0.5 \%$ & 10.9 & 10.9 \\
\hline L58 & $0.4 \%$ & 3.5 & 3.5 \\
\hline L112 & $1.5 \%$ & 6.2 & 6.3 \\
\hline L113 & $1.0 \%$ & 3.5 & 3.5 \\
\hline L114 & $0.7 \%$ & 2.6 & 2.6 \\
\hline L81 & $1.0 \%$ & 16.0 & 16.2 \\
\hline L82 & $0.3 \%$ & 5.8 & 5.8 \\
\hline L87 & $0.6 \%$ & 5.6 & 5.6 \\
\hline L91 & $0.5 \%$ & 8.4 & 8.4 \\
\hline L93 & $0.6 \%$ & 1.9 & 1.9 \\
\hline L99 & $4.1 \%$ & 34.0 & 35.5 \\
\hline L100 & $4.8 \%$ & 27.7 & 29.1 \\
\hline L80 & $1.2 \%$ & 4.8 & 4.9 \\
\hline L86 & $1.1 \%$ & 6.3 & 6.4 \\
\hline L89 & $1.2 \%$ & 5.0 & 5.0 \\
\hline L95 & $5.1 \%$ & 39.6 & 41.7 \\
\hline L126 & $7.4 \%$ & 53.4 & 57.7 \\
\hline L149 & $3.6 \%$ & 19.5 & 20.2 \\
\hline
\end{tabular}




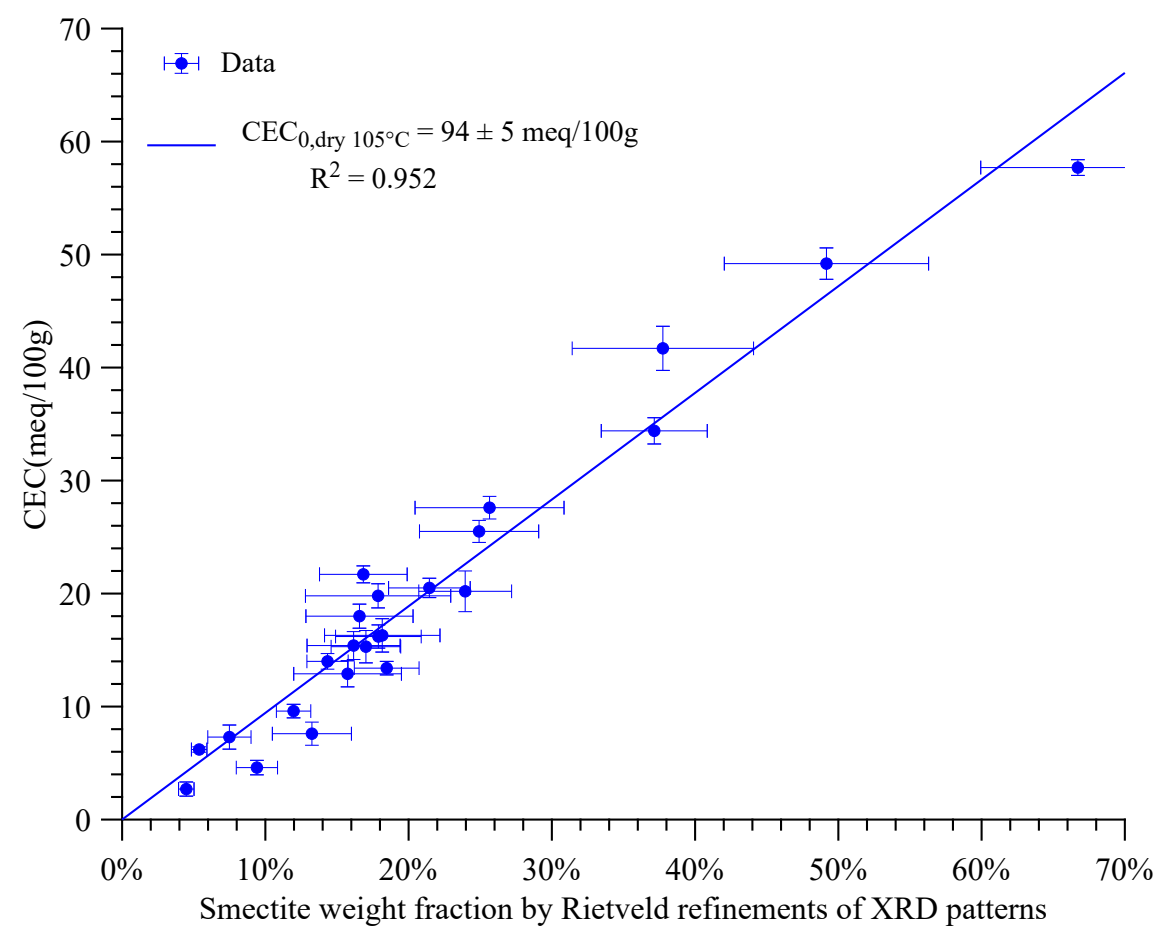

Figure D.1: Smectite content versus CEC, after correction of the CEC value for the water content, based on the water loss at $105^{\circ} \mathrm{C}$. The slope and regression coefficient are indicated on the figure. 